\title{
Evaluation of Radar Quantitative Precipitation Estimates (QPEs) as an Input of Hydrological Models for Hydrometeorological Applications
}

\author{
DAYAL WIJAYARATHNE \\ School of Geography and Earth Sciences, McMaster University, Hamilton, Ontario, Canada \\ SUDESH BOODOO \\ Cloud Physics and Severe Weather Research Section, Environment and Climate Change Canada, \\ King City, Ontario, Canada \\ PAUlin COULIBALY \\ Department of Civil Engineering, and School of Geography and Earth Science, McMaster \\ University, Hamilton, Ontario, Canada \\ DAVID SILLS \\ Department of Civil and Environmental Engineering, University of Western Ontario, \\ London, Ontario, Canada
}

(Manuscript received 4 February 2020, in final form 4 June 2020)

\begin{abstract}
Weather radar provides real-time, spatially distributed precipitation estimates, whereas traditional gauge data are restricted in space. The use of radar quantitative precipitation estimates (QPEs) as an input of hydrological models for hydrometeorological applications has increased with the development of weather radar worldwide. New dual-polarization technology and algorithms are showing improvements to radar QPEs. This study evaluates radar QPEs from C-band radar at King City, Canada (WKR), and NEXRAD S-band radar at Buffalo, New York (KBUF), to verify the reliability and accuracy for operational use in the Humber River (semiurban) and Don River (urban) watersheds in the Greater Toronto Area (GTA), Canada. Twenty rainfall events that occurred from 2011 to 2017 were determined from hourly gauge measurements and compared with nine radar QPEs. Rain rates were estimated with different algorithms using three dualpolarized reflectivity values: horizontal reflectivity $Z$, differential reflectivity $Z_{\mathrm{DR}}$, and specific differential phase $K_{\mathrm{DP}}$. The correlation coefficient, bias, detection, and root-mean-square error were calculated and averaged over all events for each gauge station to show the spatial distribution and in a similar pattern to represent the variation by the event. The quality of the results in terms of accuracy and reliability indicates that the radar QPEs from KBUF S-band and WKR C-band multiparameter rain rate estimators can be effectively used as precipitation forcing of hydrological models for hydrometeorological applications. The high spatiotemporal resolution, long-term data archive, and good percent detection of radar QPEs can facilitate hydrometeorological applications by providing a continuous time series for hydrological models.
\end{abstract}

\section{Introduction}

There is ample evidence of an increase in extreme weather events during the twenty-first century, mainly due to climate change (Jentsch et al. 2007; Pachauri et al. 2014). After earthquakes and tsunamis, floods have

Corresponding author: Dayal Wijayarathne, wijayard@ mcmaster.ca been the deadliest natural disaster in the world over recent decades (Balica et al. 2013). Enhanced meteorological extremes accelerate the hydrological cycle and cause fluctuations in the discharge that cause floods (Han and Coulibaly 2017; Reggiani and Weerts 2008). In Canada, floods are identified as the most frequent natural hazard to life, property, economy, and environment in the past century and show an increasing trend over time (Bowering et al. 2014). As reported by Public 
Safety Canada, the estimated total costs of massive floods in Canada from 1900 to 2016 were estimated at almost 36 billion Canadian dollars (Public Safety Canada 2019). Therefore, flood mitigation measures are vital for flood-prone regions, and an enhanced flood forecasting system is an essential part of flood mitigation.

A proper flood forecasting system can deliver precise and reliable forecasts with adequate lead time (Cloke and Pappenberger 2009). Over the past few decades in Canada, flood forecasting and nowcasting had been conducted based on hydrological modeling using lumped, semidistributed, and distributed models (Moradkhani and Sorooshian 2008). Different hydrological models are being used across Canada for flood forecasting (Zahmatkesh et al. 2019). Even though different static and dynamic precipitation data are available in Canada, the precipitation input of hydrological models rely mostly on in situ rain gauge data (Unduche et al. 2018; Zahmatkesh et al. 2019). Point data from gauges use different interpolation techniques to make spatially distributed precipitation grids for hydrological modeling applications (Nerini et al. 2015). Widely used interpolation techniques introduce errors to precipitation estimates, mainly due to their inability to quantify interpolation uncertainty (Boluwade et al. 2018; Tabios and Salas 1985). In operational hydrology, spatially distributed precipitation estimates with a high temporal resolution are preferred to use as the meteorological input for hydrological models.

Nowadays, with the worldwide development of weather radar infrastructure, there is considerable interest in real-time, spatially distributed precipitation information derived from radar over conventional rain gauge data for hydrometeorological applications such as flood forecasting (Thorndahl et al. 2017). Also, the use of hydrological models in combination with radar estimated quantitative precipitation estimates (QPEs) as a substitute to rain gauges has evolved recently mainly with the advances in radar hardware, data processing, and numerical models (Şensoy et al. 2016). Rain gauges are reliable instruments for rainfall point measurements, but the rainfall varies both in space and time, which is not captured by typical rain gauge networks (Dhiram and Wang 2016). Unlike gauges, radar produces real-time, spatially, and temporally continuous data that enhances hydrometeorological applications (e.g., flood forecasting) in small urban watersheds (Thorndahl et al. 2017). In relatively large watersheds with sparse rain gauge density, weather radar provides a reliable source of precipitation input for hydrological models that facilitate hydrometeorological applications (Price et al. 2014).

The concept of radar estimated QPEs for hydrological applications first appeared at the urban storm drainage conference in Sweden in 1984 (Einfalt et al. 2004). In conjunction with the advances in radar systems, computer power, and hydrological models over the past decades, the application of radar QPEs as precipitation input for hydrological models has been increased since then (Beneti et al. 2019; Khan et al. 2019; Meischner 2005; Ran et al. 2018). Different countries produce commercial weather radar QPEs providing a grid with precipitation accumulation over time [e.g., Next Generation Weather Radar (NEXRAD) in the United States, Nimrod in the United Kingdom, and Radar-Online-Aneichung (RADOLAN) in Germany] (Krajewski et al. 2010a; Marx et al. 2006; Moore et al. 2004; Wijayarathne et al. 2020). Also, the accuracy and reliability of weather radar QPEs have been significantly improved with the use of dual-polarized radar products such as specific differential phase $K_{\mathrm{DP}}$ and differential reflectivity $Z_{\mathrm{DR}}$ (Bringi et al. 2011; Chandrasekar et al. 2013; Hall et al. 2015; Park et al. 2005; Sugier et al. 2006; Dufton 2016; Ryzhkov et al. 2005). Hydrometeorological applications in urban and semiurban watersheds are benefited mostly from real-time operational weather radar QPEs. For example, local operational warning systems based on weather radar QPEs have been developed to help emergency planning worldwide (Thorndahl et al. 2017; Vivoni et al. 2006; Krajewski et al. 2017; Hapuarachchi et al. 2011). For example, the Weather Research and Forecasting (WRF) Model, which is a fully coupled atmospheric-land surface/hydrologic model, has been used to forecast heavy precipitation events by assimilating conventional observations and weather radar products (Mazzarella et al. 2020). However, the use of radar QPEs in operational hydrology is yet to be implemented in Canada.

Research in Canadian weather radar began under the project Stormy Weather at the end of the Second World War in 1943 (Sills and Joe 2019; Douglas 1990). Since then, the radar network was gradually expanded, and the application of weather radar in hydrometeorological applications has evolved significantly. The current Canadian radar network includes 31 radar stations and covers most of the populated areas (Joe and Lapczak 2002). This radar network provides reflectivity measurement at a range of $256 \mathrm{~km}$ in a radius around the radar site and a Doppler coverage at a range of $120 \mathrm{~km}$ around the site (Mekis et al. 2018). The King City weather radar (WKR) facility located in the north of Toronto, Ontario, is the first Doppler radar system to be designed and operated in Canada specifically for the weather radar observations (Crozier et al. 1991). In 2004, King City C-band radar $(\sim 5 \mathrm{~cm})$ was upgraded to dual-polarization technology and operates in simultaneous transmit and receive mode (Boodoo et al. 2015). 
Other than the Canadian weather radar systems, the American radar system NEXRAD covers areas close to the U.S.-Canada border, where most of the Canadian population resides (Fortin et al. 2015). For example, the NEXRAD radar station at Buffalo (KBUF) covers the Greater Toronto Area (GTA) in Canada. NEXRAD is a Doppler weather radar network developed by National Weather Service (NWS) of the United States that comprises 160 weather surveillance radar across the United States (Mekis et al. 2018; Weber et al. 2007). Currently, both single-polarimetric rain rate $R(Z)$ algorithms and dual-polarimetric (DP-QPEs) rain-rate algorithms are used by NWS for the NEXRAD radar in the United States (Ryzhkov et al. 2005; Berkowitz et al. 2013). Two levels of NEXRAD products are available to the public in the National Centers for Environmental Information (NCEI) archives (NOAA 2018). Level II NEXRAD data are the three meteorological base data: reflectivity, mean radial velocity, and spectrum width. Level III NEXRAD, which is mostly used in hydrological studies, are derived from Level II data from multiple weather radars covering the area (Chen and Farrar 2007; Xie et al. 2006).

Even though the radar QPEs had been used for nearly 30 years in hydrological applications, the use of radar QPEs as an input of hydrological models is still controversial mainly due to the associated errors (Rabiei and Haberlandt 2015; Wang et al. 2015). The accuracy is contentious due to errors in measurements and reflectivityrain intensity conversions and causes uncertainties in hydrological models (Dai et al. 2018). Since radar provides indirect rainfall measurements, errors can be induced by the variability of the drop size distribution (Maki et al. 2005), attenuation (Park et al. 2005), ground clutter (Hubbert et al. 2009), radar miscalibration (Ayat et al. 2018), partial beam blocking (P. C. et al. 2013), evaporation, advection, vertical air motion, radome wetting, and beam filling (Thorndahl et al. 2017; Wang et al. 2015). Therefore, evaluation is essential before using radar QPEs in hydrometeorological applications.

When compared to the United States, studies on the radar QPE evaluation in Canada is relatively sparse. The first study was conducted to assess the benefits of weather radar in hydrological studies in the Red Deer River basin, Alberta, using Alberta Research Council's S-band radar (Barge et al. 1979). The estimated precipitation using the Marshall-Palmer $Z-R$ relation for the James River subbasin by the two methods only agreed to within $15 \%$ throughout a stormy 6 -day period. Another study compared the mean areal rainfall computed using the Theissen polygon method and weather radar in the Yamaska river watershed using McGill S-band radar data (Damant et al. 1983). The error between 3\% and $69 \%$ were reported for 13 storms compared to the gauge data. A performance assessment of Woodbridge C-band radar QPEs using the $Z=295 R^{1.43}$ algorithm for the Grand River basin above Cambridge in Southern Canada was conducted over six storm events from 1975 to 1978 by Dalezios in 1988. A systematic mean storm radar bias, which varies from 0.37 to 2.56 , was observed between gauge and radar storm accumulations. Schell et al. (1992) examined the capability of radar QPEs to enhance the storm hydrographs simulation for six rainfall events occurring in 1986 and 1987 over St. Dominique watershed $\left(8.13 \mathrm{~km}^{2}\right)$ in southwestern Quebec using McGill weather $\operatorname{radar}\left(Z=200 R^{1.6}\right)$. A minor improvement in hydrograph simulation was observed for high-intensity rainfall events when radar QPEs were used as input to the Hydrological Model (HYMO). Fassnacht (2003) investigated the radar QPEs versus gridded gauge data as precipitation input to hydrological model WATCLASS for the Upper Grand River basin in central, southwestern Ontario, Canada, using King City C-band for five winters from 1993 to 1997. The radar QPEs outperformed the gauge data in the model simulating runoff volumes with reported underestimation of $41.7 \%$ and $0.3 \%$ for gauge and radar QPE, respectively. Most recently, Boodoo et al. (2015) evaluated several radar QPEs from the King City C-band dual-polarized radar for a flash flooding in the city of Toronto after a heavy rainfall event over a 2-h period on 8 July 2013. This study evaluated total storm accumulations of WKR C-band QPE algorithms based on different dual-polarized products, horizontal reflectivity $Z$, differential reflectivity $Z_{\mathrm{DR}}$, specific differential phase $K_{\mathrm{DP}}$, and specific attenuation at horizontal polarization $A$. KBUF NEXRAD S-band dual-polarized radar at Buffalo, New York, and gauges were used as the reference. The study demonstrated good performance from the algorithms based on $K_{\mathrm{DP}}$ and $A$. The only evaluation of NEXRAD radar QPEs in Canadian watersheds (to the best of our knowledge) was conducted in 2007 by Chen and Farrar in 2007. A correlation of 0.78 was reported between the daily accumulation NEXRAD radar QPEs and rain gauge measurements. Also, $62 \%$ of NEXRAD radar QPEs underestimated the precipitation, especially for small rainfall events. Nevertheless, a more continuous pattern of rainfall was observed in radar precipitation surface than the interpolated gauge surface.

Currently, a satisfactory technique to incorporate radar QPEs for hydrological models in Canadian watersheds in real time or near-real time does not exist. Also, a robust method to correct biases in radar QPEs before using them as precipitation input to hydrological models has not been evaluated to date. Both bias correction of radar using radar-gauge merging and 
eventually incorporating radar QPEs into hydrological models depends on the accuracy and reliability of radar QPEs (Wijayarathne et al. 2020). A few studies have evaluated radar QPEs in Canadian watersheds but were limited to a single $Z-R$ rain rate relationship, mostly Marshall-Palmer (Barge et al. 1979; Damant et al. 1983; Dalezios 1988; Schell et al. 1992). Also, many of the past studies have evaluated monthly, daily, or accumulations over storms (Barge et al. 1979; Dalezios 1988; Boodoo et al. 2015). However, hydrometeorological applications such as operational flood forecasting require high temporal (hourly or subhourly) precipitation inputs. Therefore, an extensive evaluation of existing radar QPEs in Canadian watersheds using high temporal (hourly) radar QPEs is necessary. Floods can be triggered either by high intense rainfall occurring in short periods or persistent low intense rain for a more extended period (Diakakis et al. 2016). Therefore, a wide range of rainfall intensities needs to be considered to draw more reliable conclusions. Evaluating the accuracy and reliability of different radar QPEs would help develop ensemble prediction systems (EPSs) by using various precipitation ensembles derived from different $Z-R$ algorithms to force the hydrological models (Cloke and Pappenberger 2009; Moradkhani and Sorooshian 2008). Thus, a comprehensive evaluation is necessary before using radar QPEs as input to hydrological models with high confidence.

This study is the first attempt to evaluate nine hourly radar QPEs for 20 rainfall events that reported in spring, summer, and fall periods from 2011 to 2017 over two watersheds in the GTA, Canada: Humber River (semiurban) and Don River (urban) watersheds. Two KBUF NEXRAD S-band radar QPEs at Buffalo, New York, United States, and seven WKR C-band dual-polarized radar QPEs at King City, Ontario, Canada, are used for the study. The goals of this study are 1) to evaluate hourly radar QPEs/algorithms to assess which best suits the urban watersheds in GTA, Canada; 2) to illustrate the performance of radar QPEs for different rainfall events; and 3) to assess the performance of radar QPEs at different rain intensities and in different seasons. The outcome of this research will help to identify the best radar QPE to be implemented in the two urban watersheds in GTA, Ontario, Canada. Also, the evaluation of radar QPEs will facilitate the radar-gauge merging and, subsequently, hydrometeorological applications such as real-time flood forecasting.

\section{Study area}

The Humber River watershed and Don River watershed are the two watersheds of interest (Fig. 1). Both watersheds are in the Greater Toronto Area and are currently managed by the Toronto and Region Conservation Authority (TRCA). These watersheds are urban and encompass many impervious areas; hence they are considered flood-prone. Recent flood events (e.g., 2013 Toronto flash flood) have emphasized the need for enhanced flood forecasting systems that deliver precise and reliable forecasts with appropriate lead time.

The Humber River watershed is a part of the Great Lakes basin and is considered the largest watershed in the GTA. The watershed encompasses an area of $911 \mathrm{~km}^{2}$. Land uses consist of approximately 54\% rural land, 33\% urban land, and the remaining $13 \%$ urbanizing land (TRCA 2019b). This watershed is semiurban and home to over 800000 residents. A detailed description of the Humber River watershed can be found in the TRCA Watershed Features-Humber River website (TRCA 2019b ).

The Don River watershed is considered a fully urbanized watershed with approximately $80 \%$ developed areas and the remaining area being wetlands, forest, croplands, and pasture (Natural Resources Canada 2009). The watershed is approximately $350 \mathrm{~km}^{2}$ in size, and the catchment is home to over 1 million residents. For further details of the Don River watershed, readers are referred to the TRCA Don River website (TRCA 2019a).

\section{Materials and methods}

\section{a. Data description}

\section{1) RAIN GAUGE}

One-hour accumulations of surface rainfall data provided by tipping-bucket rain gauges from 2011 to 2017 were gathered from TRCA data archives. The temporal resolution of received rainfall data ranges from 5 to $60 \mathrm{~min}$. TRCA operates 18 real-time tipping-bucket rain gauges distributed across the two watersheds. All gauges are located within the $\sim 40-\mathrm{km}$ radius range of King City (WKR) Canadian C-band radar station (Fig. 2). Apart from Canadian radar, both watersheds have an excellent radar spatial coverage from the Buffalo (KBUF) NEXRAD S-band radar. All TRCA gauge stations are located within the usable range $(<180 \mathrm{~km})$ of KBUF NEXRAD S-band radar station (Fig. 2).

\section{2) KBUF NEXRAD S-BAND RADAR QPES}

NEXRAD Level III S-Band radar estimated precipitation data recorded at the Buffalo radar $\left(42.94639^{\circ} \mathrm{N}\right.$, $78.72278^{\circ} \mathrm{W}$ ) for the same period as gauge data were downloaded from the National Centers for Environmental Information (NCEI) archives (NOAA 2018). Two NEXRAD Level III QPE products, One-Hour Precipitation 


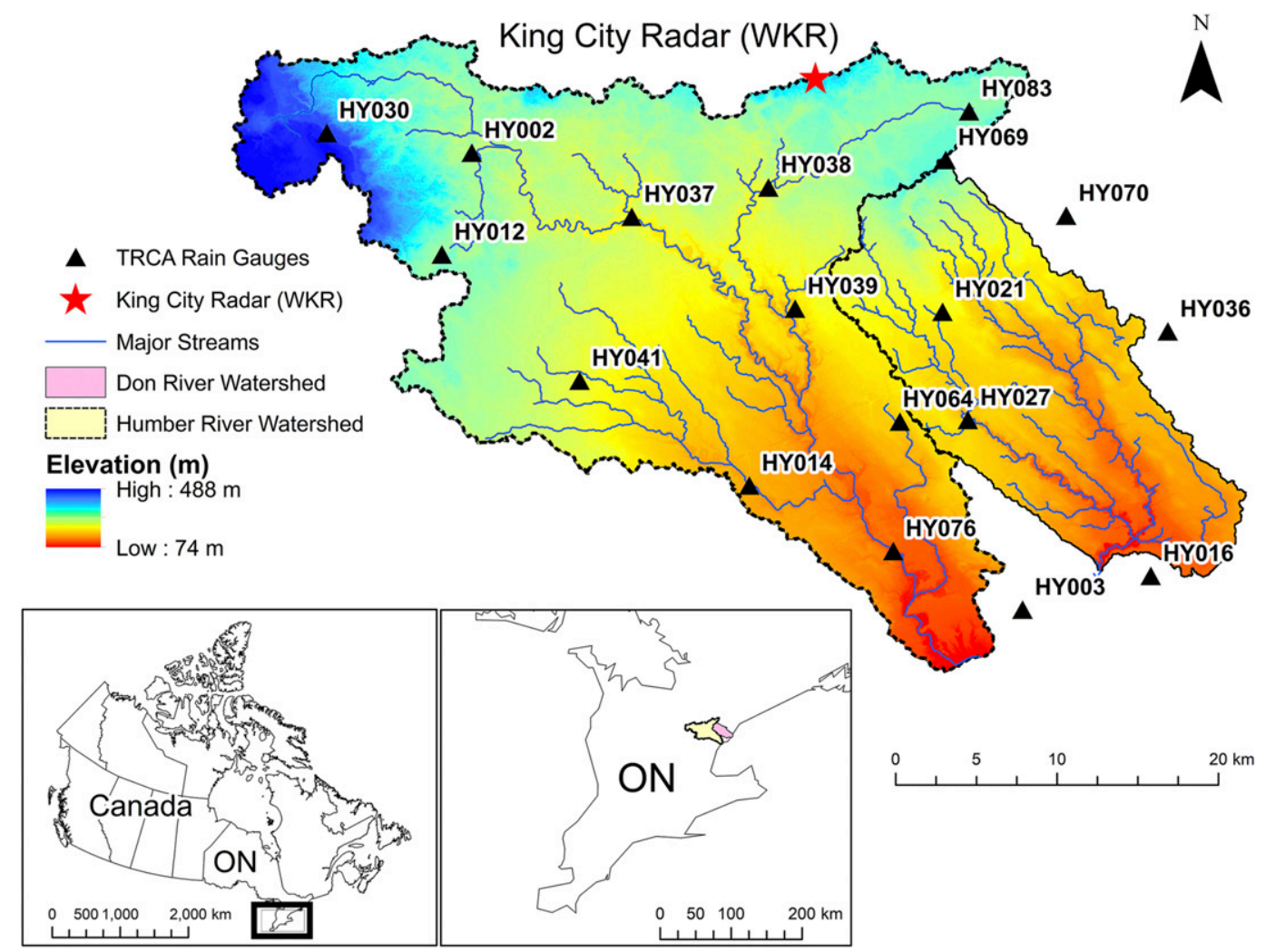

FIG. 1. Humber River and Don River watersheds in GTA.

(N1P/78), and Digital Precipitation Array (DPA/81), were used in this study. N1P/78 is a radar estimated 1-h precipitation accumulation at the volume scan time on a $1.1 \mathrm{~nm} \times 1^{\circ}$ grid. The DPA/81 is a radar estimated $1-\mathrm{h}$ precipitation accumulation on the 4.7625-km Hydrologic Rainfall Analysis Projection (HRAP) grid.

\section{3) KING City WKR C-BAND QPES}

Polarimetric plan position indicator (POLPPI) scans at $0.5^{\circ}$ elevation completed in $\sim 1$ min with $0.25 \mathrm{~km} \times$ $0.5^{\circ}$ range and azimuthal resolution and repeated in a 10-min cycle were collected from Environment and Climate Change Canada (ECCC) data archives.

\section{b. Data preprocessing and derivation of rainfall time series}

\section{1) KBUF NEXRAD S-BAND RADAR}

Both NEXRAD N1P/78 and DPA/81 products have been calculated using the Precipitation Processing System (PPS) algorithm using $R=0.017 Z^{0.714} Z-R$ relationship (Fulton et al. 1998). Raw data are stored as ASCII format. The NEXRAD S-band radar QPEs comprise an accumulation of precipitation over $1 \mathrm{~h}$. The NEXRAD S-band radar QPEs at 1-h intervals were exported into ASCII format using NOAA's Weather and Climate Toolkit (WCT). The binary NEXRAD radar QPE data were then converted into GeoTIFF files using batch processing capability of the terminal version of WCT. Several scripts were written in MATLAB, Python, and batch files to facilitate data processing (Guzman et al. 2013). ArcGIS 10.6.1 was used to reproject gridded NEXRAD data into Universal Transverse Mercator (UTM) coordinate system. Reprojected NEXRAD grids were then clipped into watershed boundaries with the use of modeling tools in ArcGIS.

\section{2) WKR C-BAND RADAR}

Radar QPEs were estimated for each of the POLPPI scans at 10-min intervals using different rain rate estimator algorithms listed in Table 1. In this study, the modified ZPHI attenuation correction, which depends on identified hotspots, was used to correct $Z$ and $Z_{\mathrm{DR}}$ for attenuation. For further details on ZPHI attenuation correction, readers refer to Ryzhkov et al. $(2006,2007)$ and Boodoo et al. (2015). After attenuation correction, rain rates are calculated using $R(Z), R\left(Z, Z_{\mathrm{DR}}\right), R(Z$, $\left.K_{\mathrm{DP}}\right)$, and $R\left(K_{\mathrm{DP}}, Z_{\mathrm{DR}}\right)$ algorithms. Rain rates using both raw and attenuation corrected $Z$ and $Z_{\mathrm{DR}}$ were estimated using conventional Marshall-Palmer $\left(R=0.0365 Z^{0.625}\right)$ 


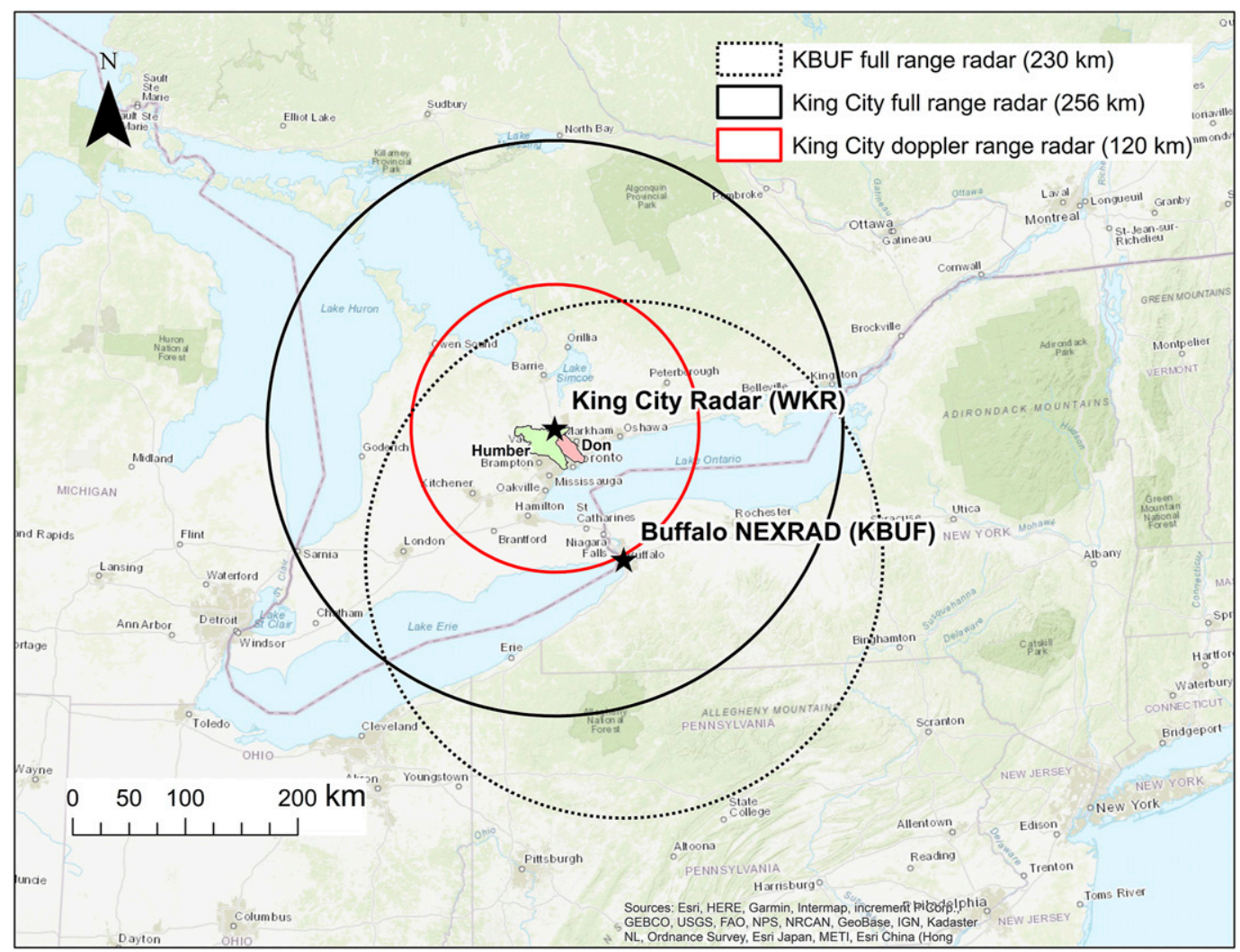

FIG. 2. Spatial coverage of radar from King City Canadian C-band radar (WKR) and Buffalo, New York, NEXRAD S-band radar (KBUF).

algorithm (Marshall and Palmer 1948). Also, the U.S.derived $Z-R$ relationship by Fulton et al. (1998) was used to derive radar QPEs using WKR C-band $\operatorname{radar}(Z)$ to compare the rainfall accumulation in the overlapping radar (NEXRAD and WKR) coverage with the same $Z-R$ relationship. Since the coefficients of the $Z-R$ relationship by Fulton et al. (1998) are much similar to the $Z-$ $R$ relationship suggested by Richards and Crozier (1983) for WKR radar, the effects of attenuation, height difference and other factors in the resulting accumulations can be compared. Moreover, a combined $Z$ and $K_{\mathrm{DP}}$ algorithm using a threshold on $K_{\mathrm{DP}}$ and $Z$ was estimated using algorithms $R=0.017 Z^{0.714}$ and $R=33.8 K_{\mathrm{DP}}^{0.79}$, suggested by Brandes et al. (2002). Furthermore, two multiparameter rain-rate estimators, $R\left(Z, Z_{\mathrm{DR}}\right)$ and $R\left(K_{\mathrm{DP}}, Z_{\mathrm{DR}}\right)$, were used to estimate rainfall for the evaluation (Bringi et al. 2011).

An averaging window of $11 \times 11$ in range and azimuth of radar-derived accumulations centered over the nearest gauge location was used to compare with rain

TABLE 1. List of rain-rate estimators for radar QPEs.

\begin{tabular}{|c|c|c|c|}
\hline Product & Description & Formula & Reference \\
\hline $\mathrm{C} 1$ & Standard Marshall-Palmer with uncorrected $Z$ & $R=0.0365 Z^{0.625}$ & Marshall and Palmer (1948) \\
\hline $\mathrm{C} 2$ & Standard Marshall-Palmer with attenuation corrected $Z$ & $R=0.0365 Z^{0.625}$ & Marshall and Palmer (1948) \\
\hline $\mathrm{C} 3$ & Attenuation-corrected $Z$ but using NEXRAD $R(Z)$ & $R=0.017 Z^{0.714}$ & Fulton et al. (1998) \\
\hline $\mathrm{C} 4$ & $\begin{array}{l}\text { Combined } Z \text { and } K_{\mathrm{DP}} \text { algorithm using a threshold } \\
\text { on } K_{\mathrm{DP}}\end{array}$ & $\begin{array}{l}R=0.017 Z^{0.714} \\
R=33.8 K_{\mathrm{DP}}^{0.79}\end{array}$ & Brandes et al. (2002) \\
\hline C5 & Combined $Z$ and $K_{\mathrm{DP}}$ algorithm using a threshold on $Z$ & $\begin{array}{l}R=0.017 Z^{0.714} \\
R=33.8 K_{\mathrm{DP}}^{0.79}\end{array}$ & Brandes et al. (2002) \\
\hline C6 & Multiparameter rain rate estimator using $Z$ and $Z_{\mathrm{DR}}$ & $R=0.0058 Z^{0.91} 10^{-0.209 Z_{\mathrm{DR}}}$ & Bringi et al. (2011) \\
\hline $\mathrm{C7}$ & Multiparameter rain rate estimator using $K_{\mathrm{DP}}$ and $Z_{\mathrm{DR}}$ & $R=37.9 K_{\mathrm{DP}}^{0.89} 10^{-0.072 Z_{\mathrm{DR}}}$ & Bringi et al. (2011) \\
\hline N1 & NEXRAD Level III (N1P) & $R=0.017 Z^{0.714}$ & Fulton et al. (1998) \\
\hline $\mathrm{N} 2$ & NEXRAD Level III (DPA) & $R=0.017 Z^{0.714}$ & Fulton et al. (1998) \\
\hline
\end{tabular}


TABLE 2. Description of events.

\begin{tabular}{|c|c|c|c|c|c|c|c|c|c|}
\hline \multirow[b]{2}{*}{ Event No. } & \multirow[b]{2}{*}{ Start date } & \multirow[b]{2}{*}{ UTC } & \multirow[b]{2}{*}{ End date } & \multirow[b]{2}{*}{ UTC } & \multirow[b]{2}{*}{ Season } & \multicolumn{3}{|c|}{ Rainfall (mm) } & \multirow[b]{2}{*}{ Duration $(\mathrm{h})$} \\
\hline & & & & & & Avg & Max & Min & \\
\hline 1 & 29 Nov 2011 & 0400 & 29 Nov 2011 & 2200 & Fall & 36.2 & 53.4 & 4.6 & 19 \\
\hline 2 & 1 Jun 2012 & 0800 & 1 Jun 2012 & 2300 & Summer & 27.7 & 39 & 7.6 & 16 \\
\hline 3 & 28 May 2013 & 2000 & 29 May 2013 & 0800 & Spring & 33.95 & 60 & 3 & 14 \\
\hline 4 & 8 Jul 2013 & 1800 & 9 Jul 2013 & 0200 & Summer & 44.92 & 93.8 & 0 & 9 \\
\hline 5 & 31 Jul 2013 & 1900 & 1 Aug 2013 & 1000 & Summer & 34.76 & 50 & 1 & 16 \\
\hline 6 & $28 \mathrm{Jul} 2014$ & 0000 & 28 Jul 2014 & 1200 & Summer & 28.74 & 85 & 0 & 13 \\
\hline 7 & 6 Sep 2014 & 0000 & 6 Sep 2014 & 1000 & Fall & 26.6 & 52.6 & 0 & 11 \\
\hline 8 & 20 Apr 2015 & 0300 & 20 Apr 2015 & 1900 & Spring & 20.45 & 32 & 0 & 17 \\
\hline 9 & 30 May 2015 & 1500 & 31 May 2015 & 2300 & Spring & 42.34 & 66 & 10 & 33 \\
\hline 10 & 8 Jun 2015 & 0000 & 8 Jun 2015 & 1300 & Summer & 28.33 & 44.2 & 0 & 14 \\
\hline 11 & 27 Jun 2015 & 1700 & 28 Jun 2015 & 2100 & Summer & 39.07 & 57 & 16 & 29 \\
\hline 12 & 28 Oct 2015 & 0700 & 28 Oct 2015 & 2300 & Fall & 30.12 & 49.8 & 0 & 17 \\
\hline 13 & 10 Nov 2015 & 1900 & 11 Nov 2015 & 1100 & Fall & 13.2 & 20.4 & 0 & 17 \\
\hline 14 & 13 Aug 2016 & 1600 & 14 Aug 2016 & 0100 & Summer & 24.44 & 45.2 & 0 & 10 \\
\hline 15 & 16 Aug 2016 & 0800 & 16 Aug 2016 & 1900 & Summer & 16.32 & 34.4 & 1 & 12 \\
\hline 16 & 23 Jun 2017 & 0500 & 23 Jun 2017 & 1400 & Summer & 37.33 & 65.2 & 1 & 10 \\
\hline 17 & 20 Jul 2017 & 1500 & 20 Jul 2017 & 1700 & Summer & 19.86 & 41.6 & 0 & 3 \\
\hline 18 & 27 Jul 2017 & 0000 & 27 Jul 2017 & 1500 & Summer & 9.91 & 15.2 & 2 & 16 \\
\hline 19 & 22 Aug 2017 & 1200 & 22 Aug 2017 & 2300 & Summer & 11.8 & 24.2 & 0 & 14 \\
\hline 20 & 18 Nov 2017 & 2200 & 19 Nov 2017 & 0800 & Fall & 11.62 & 20 & 0 & 11 \\
\hline
\end{tabular}

gauge amounts. Pixel averaging permits restraining the effect of wind drift that can be very significant (Lack and Fox 2007). Since range bins are $0.25 \mathrm{~km}$ and azimuths are at $0.5^{\circ}$ resolutions, 11 pixels in range $=11 \times$ $0.25 \mathrm{~km}=2.75 \mathrm{~km}$ and 11 pixels in azimuth $=11 \times 0.5=$ $5.5^{\circ}$, at an average gauge distance of $40 \mathrm{~km}$, this works out to about $3.8 \mathrm{~km}$. Radar estimated rain rates are assumed to be constant over the scanning time interval of $10 \mathrm{~min}$. The 10 -min radar rainfall measurements are accumulated to obtain the total hourly rainfall time series.

\section{c. Evaluation of radar QPEs}

Twenty rainfall events, totaling $297 \mathrm{~h}$ of rainfall that occurred in spring, summer, and fall periods from 2011 to 2017 (Table 2), were identified from hourly rain gauge data and used as a ground reference. Winter precipitation was excluded from this study because the algorithms are only valid for liquid precipitation and do not account for possible bright band contamination (Boodoo et al. 2015; Wijayarathne et al. 2020). Several criteria such as intensity, speed, storm size, availability of both gauge and radar precipitation, missing values, satisfactory accumulation of rainfall, suitable duration, coverage of the watershed, and adequate discharge at the outlet of the watershed were considered for event selection. The duration of an event was determined as the time wherein at least half of the gauges recorded a precipitation amount $>0 \mathrm{~mm}$ to the time where half of the gauges start rerecording zero (Krajewski et al. 2010b;
Wijayarathne et al. 2020). Hourly accumulations from gauges and nine radar QPEs listed in Table 1 for each event were calculated. The summary statistics were computed between each gauge-pixel pair, and missing values were ignored during the comparison. The correlation coefficient $[r$; Eq. (1)], bias [b; Eq. (2)], radar detection (Young and Brunsell 2008) [d; Eq. (3)], and RMSE [Eq. (4)] were calculated between radar QPEs and gauge for each event separately. These metrics were averaged over all events for each gauge station to show the spatial distribution and in a similar pattern to represent the variation by the event:

$$
\begin{aligned}
r & =\frac{\sum\left(P_{G}-\bar{P}_{G}\right)\left(P_{R}-\bar{P}_{R}\right)}{\sqrt{\sum\left(P_{G}-\bar{P}_{G}\right)^{2} \sum\left(P_{R}-\bar{P}_{R}\right)^{2}}}, \\
b & =\frac{\sum P_{R}-\sum P_{G}}{\sum P_{G}} \times 100, \\
d & =\frac{n_{P_{R}}>0, P_{G}>\text { thresh }}{n_{P_{G}}>\text { thresh }} \times 100, \\
\text { RMSE } & =\sqrt{\frac{\sum_{i=1}^{n}\left(P_{G}-P_{R}\right)^{2}}{n}},
\end{aligned}
$$

where $P_{G}$ is hourly precipitation observed by gauge; $\bar{P}_{G}$ is average hourly rain gauge measurement; $P_{R}$ is hourly radar estimated precipitation; $\bar{P}_{R}$ is average hourly radar 
estimated rainfall; $n_{P_{R}}>0, P_{G}>$ thresh, number of radar-gauge pairs that the radar reports precipitation and the corresponding rain gauge observation exceeds a specified threshold $(0 \mathrm{~mm})$; and $n_{P_{G}}>$ thresh, number of radar-gauge pairs where the rain gauge observation exceeds a specified threshold $(>0 \mathrm{~mm})$.

In this study, it is essential to notice that there is always a spatial mismatch in the precipitation estimates between radar and gauges because different volumes are sampled by rain gauges and weather radar (Grayman and Eagleson 1971). Rain gauges record time-integrated precipitation over an 8-in. diameter surface area, whereas radar instantly samples a significant volume above approximately $4 \mathrm{~km} \times 4 \mathrm{~km}$ surface (Young and Brunsell 2008). This spatial mismatch can contribute to differences in precipitation values. Also, gauges that are used as the ground truth can be unreliable due to random and systematic errors (Mekonnen et al. 2015). Random errors can be resulted by irregularities of topography and vegetation around the gauge site, poor gauge site conditions, human errors, inadequate network density, and by the disclosure to prevailing winds. Systematic errors in precipitation due to wind-induced undercatch, wetting, and evaporation losses also affect the gauges (Sevruk 1982). There is also a known low bias for tipping-bucket gauges in high precipitation events where the bucket tipping cannot keep up.

\section{Results and discussion}

Average precipitation detections with WKR C-band and KBUF NEXRAD S-band radar QPEs for each event are presented in Fig. 3a. Overall, the detection is relatively higher for all WKR C-band radar QPEs than KBUF NEXRAD QPEs and varies from event to event. This is not surprising as the study area is much closer to the C-band radar than the S-band, although it suffers from attenuation of return echoes (Borga et al. 2002). The range of detections reported for WKR C-band radar QPEs ranges from $53.5 \%$ to $96.6 \%$, and KBUF S-band radar QPE ranges from $3.0 \%$ to $92.3 \%$. The KBUF NEXRAD measures the precipitation relatively far $(\sim 106 \mathrm{~km})$ from the watershed, while WKR radar measures the precipitation just below the storm at a distance of $37 \mathrm{~km}$ at the furthest edge of the watershed. NEXRAD Level III (DPA) (hereafter N2) is competitive with all C-band radar QPEs, but detection for NEXRAD Level III (N1P) (hereafter N1) is not as good as N2. As pointed out by Young and Brunsell (2008), low detection of NEXRAD can be partially responsible for problems in both bias and correlation when compared to the gauge accumulations. It is also challenging to address the lack of detection during the calibration of hydrological models (Zhang et al. 2012; Young and Brunsell 2008). Since detection is high in WKR C-band radar QPEs, it is possible to formulate a continuous time series with a smaller number of missing data, which is often required for hydrological model calibration. Additionally, dual-polarization data from WKR are available starting in 2004; therefore, it is possible to generate a continuous time series with subhourly resolutions for hydrological models. The box plots in Fig. $3 \mathrm{~b}$ show an average detection for C-band radar QPEs is $\sim 80 \%$. The interquartile range (IQR) is relatively low for all C-band radar QPEs, and therefore, they can detect all events successfully compared to the NEXRAD QPEs.

The average correlation between radar-estimated precipitation amounts and gauge observations is reported in Fig. 3c. The average correlation for QPEs from NEXRAD (0.38-0.98) is superior to all C-band QPEs $(0.20-0.97)$. The average correlation for the $\mathrm{N} 2(0.71)$ is better than $\mathrm{N} 1(0.63)$. The path attenuation is a significant influence on radar-estimated QPEs in heavy rain events (Boodoo et al. 2015), as C-band radar beams attenuate more rapidly than KBUF NEXRAD S-band radar because of its shorter wavelength $(\sim 10 \mathrm{~cm}$ for NEXRAD and $\sim 5 \mathrm{~cm}$ for WKR). The multiparameter rain rate estimator using $K_{\mathrm{DP}}$ and $Z_{\mathrm{DR}}$ (hereafter C7) and combined $Z$ and $K_{\mathrm{DP}}$ algorithm using a threshold on $K_{\text {DP }}$ (hereafter C4) are competitive with NEXRAD radar QPEs with reported average correlations of 0.60 and 0.56 , respectively. The $\mathrm{C} 4$ and combined $Z$ and $K_{\mathrm{DP}}$ algorithm using a threshold on $Z$ (hereafter C5) show better correlation compared to other C-band radar QPEs using only Z: standard Marshall-Palmer with uncorrected $Z$ (hereafter $\mathrm{C} 1$ ), standard Marshall-Palmer with attenuation corrected $Z$ (hereafter $\mathrm{C} 2$ ), and attenuation corrected $Z$ using rain-rate estimator for NEXRAD (hereafter C3). Previously conducted research suggests that $K_{\mathrm{DP}}$ is advantageous over $Z$ for quantitative precipitation estimates (Vivekanandan et al. 1999; Brandes et al. 2001). The $K_{\mathrm{DP}}$ is not a power measurement; therefore, radar QPEs derived from $K_{\mathrm{DP}}$ are less affected by anomalous propagation, attenuation, beam blockage, and radar miscalibration (Ryzhkov et al. 2014). Also, these QPEs are known to be less sensitive to variations in drop size distributions and the existence of hail (Sachidananda and Zrnić 1987; Aydin et al. 1995). Even though $K_{\mathrm{DP}}$ is resilient to the radar errors as mentioned above, the vulnerability of $Z$ to these errors may be limiting the quality of rainfall estimates using combined algorithms. Combining radar QPEs using thresholds on $K_{\text {DP }}$ shows better performances than combined radar QPEs using thresholds on Z. All other C-band radar estimated QPEs $(\mathrm{C} 1, \mathrm{C} 2$, and $\mathrm{C} 3$ ) show relatively low average correlation (0.41, 0.43, and 0.46, respectively). After attenuation 


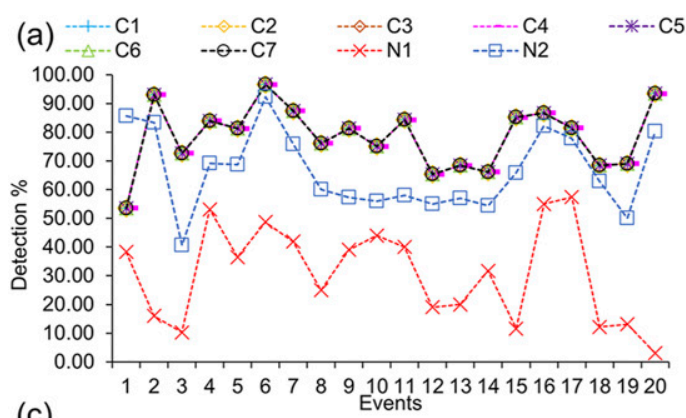

(c)

(b) $\square \mathrm{C} 1 \square \mathrm{C} 2 \square \mathrm{C} 3 \square \mathrm{C} 4 \square \mathrm{C} 5 \square \mathrm{C} 6 \square \mathrm{C} 7 \square \mathrm{N} 1 \square \mathrm{N} 2$
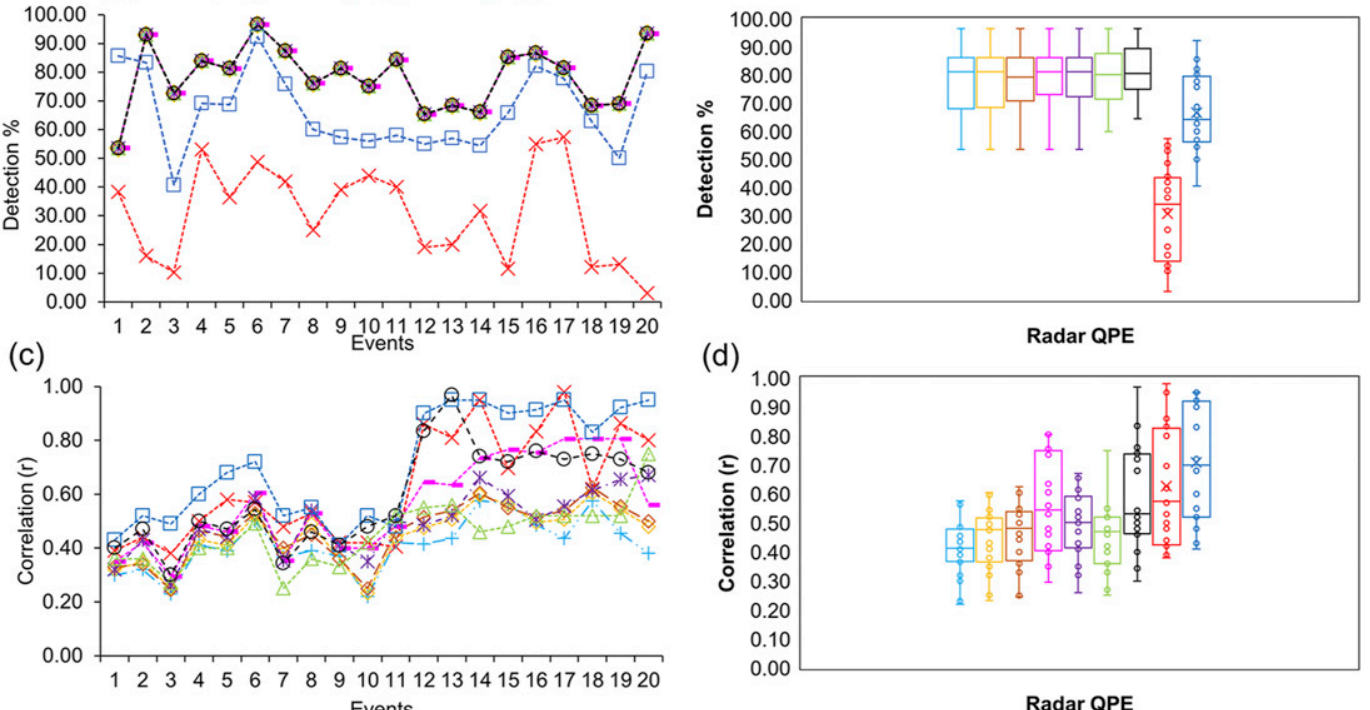

(e)

(d)
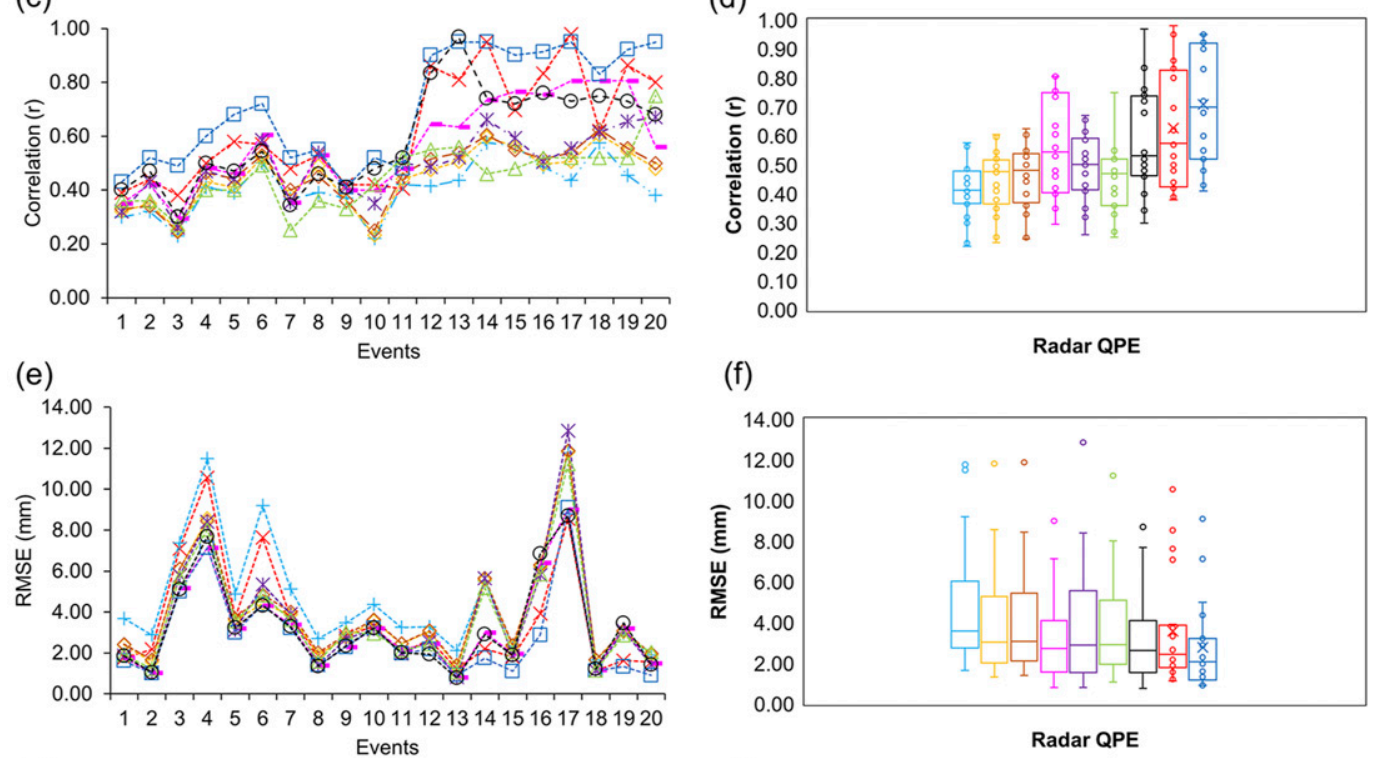

(f)

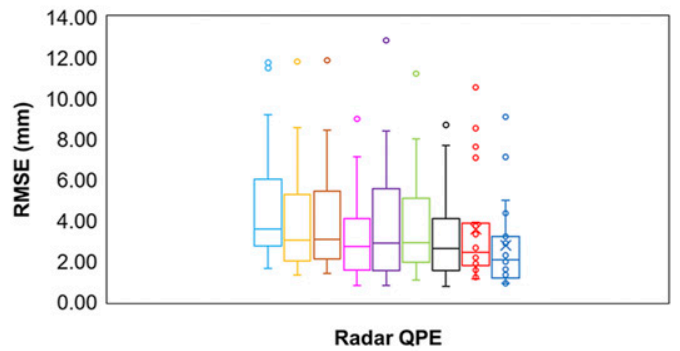

(g)

\section{(h)}
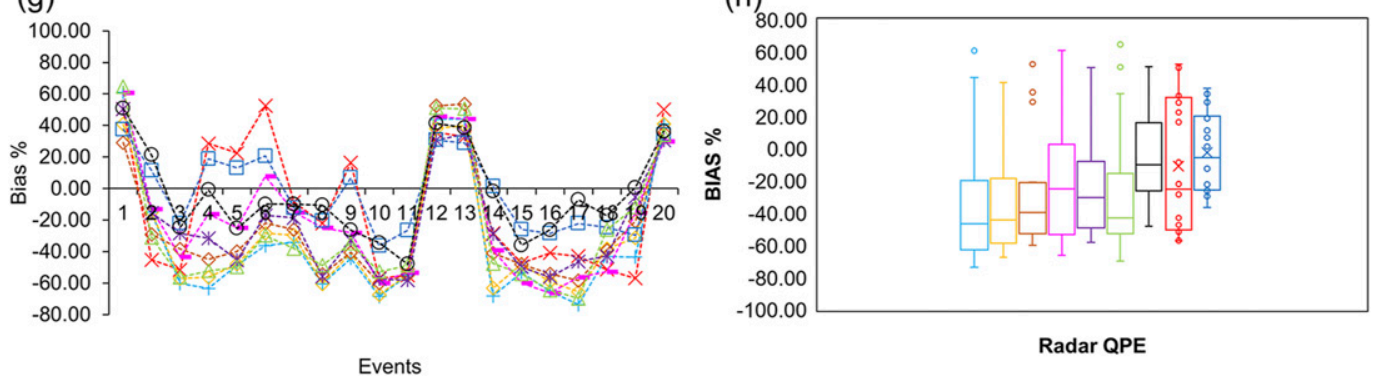

FIG. 3. (a),(b) Average detection, (c),(d) correlation, (e),(f) RMSE, and (g),(h) bias between hourly accumulation of radar QPEs and gauge measurements for each event.

correction, the correlation between the gauge and radar QPEs has been improved but does not show considerable improvement. The attenuation correction may be overshadowed by the extensive radome attenuation at WKR, resulting in poor rainfall estimates (Germann 1999; Boodoo et al. 2015). C3 shows better performances with the reported correlation of 0.46 than using Marshall-Palmer on Z (C1, 0.41 and C2, 0.43). IQRs for those QPEs (Fig. 3d) are relatively higher, implying that the correlation varies from event to event considerably. The correlation values are better for events in summer than fall and spring, especially for N2, N1, C7, and C4. For example, summer events 14-19 show $r>0.83$ while the fall and spring events 1,3 , and 7 show $r<0.5$ for $\mathrm{N} 2$. Even though the correlation is relatively low, the values are relatively persistent (mean value ranges between 0.40 and 0.60 ) for all the events for other C-band radar QPEs. N2, N1, C7, and C4 radar QPEs are more reliable for summer events than events in fall and spring. The bright band effect during early spring and late fall has affected the quality of radar QPEs for both KBUF NEXRAD S-band radar and WKR C-band radar 
(Austin and Bemis 1950; Fabry and Zawadzki 1995). For the rest of the C-band radar QPEs $(\mathrm{C} 1, \mathrm{C} 2, \mathrm{C} 3, \mathrm{C} 5$, and C6), the correlation is less, but they capture all events regardless of the period or intensity of the event. The reported correlation values are approximately similar for all radar QPEs for the less intense $\left(<5 \mathrm{~mm} \mathrm{~h}^{-1}\right)$ events (e.g., events 9 and 11). In contrast, correlation considerably varies between different radar QPEs for high-intensity $\left(\geq 5 \mathrm{~mm} \mathrm{~h}^{-1}\right.$ ) events (e.g., events 4 and 17). For high-intensity events, N2, N1, C7, and C4 perform better than other WKR C-band radar QPEs (C1, C2, C3, C5, and C6). Since these correlations are not optimum for both WKR C-band and KBUF NEXRAD QPEs for hydrological models, bias correction is necessary before using radar QPEs as a precipitation input.

Figure 3e shows the average RMSE between radargauge hourly accumulation pairs for all the events. Errors follow the same trend as the reported correlation. The least RMSE errors are reported for N2 $(2.8 \mathrm{~mm})$ followed by $\mathrm{C} 7(3.2 \mathrm{~mm})$, and errors vary considerably from event to event. Error is high for high-intensity events (e.g., events 4 and 17) and relatively small in low-intensity events (e.g., events 9 and 11). For example, average RMSE for event $4\left(10.4 \mathrm{~mm} \mathrm{~h}^{-1}\right)$ and 17 $\left(13.9 \mathrm{~mm} \mathrm{~h}^{-1}\right)$ are 8.6 and $10.5 \mathrm{~mm}$, respectively whereas for event $9\left(2.0 \mathrm{~mm} \mathrm{~h}^{-1}\right)$ and $11\left(2.0 \mathrm{~mm} \mathrm{~h}^{-1}\right)$ are 2.7 and $2.3 \mathrm{~mm}$, individually. In Fig. 3f, the least mean and IQR were reported for $\mathrm{N} 2$, which implies that errors incorporated are low, constant, and independent from the event for N2. According to Seo et al. (2015), radar calibration errors, technical limitations such as nonuniform beam filling, wind effect, growth of precipitation, anomalous propagation, variations in the $Z-R$ relationship, presence of hail, or other hydrometeors can affect the accuracy of radar QPEs. Even though attenuation and ground clutter are taken care of during signal processing, the limitations mentioned above restrict the efficiency of radar QPEs.

The event-to-event variations in $r$ and RMSE could be attributed to the differences in storm type and magnitude (Stellman et al. 2001; McKee and Binns 2016). The accuracy and reliability of radar QPEs vary along with the season (Prat and Nelson 2015). According to the results, the added value to QPEs from the radar is considerable during the summer when convective rainfall events prevail. Convective rainfall is produced through local scale lifting of air parcels and is characterized by moderate to heavy rainfalls of short duration (high intensity). Convective cells are often mischaracterized by rain gauges, but captured by weather radar (McKee and Binns 2016). On the contrary, stratiform rainfall is produced through larger-scale, regional lifting of air parcels (e.g., a low pressure system), resulting in light to moderate rainfall over a large area for a relatively long duration. Rain gauges can characterize the stratiform precipitation relatively well compared to weather radar (McKee and Binns 2016).

Figures $3 \mathrm{~g}$ and $3 \mathrm{~h}$ show the distribution of bias values and boxplots over the events. All radar QPEs underestimate the reported gauge precipitation for all events except for events $1,12,13$, and 20 . This underestimation is reported because radar QPEs are subject to both random and systematic errors. For instance, an order of $4 \%-5 \%$ of radar underestimation was stated due to wind under catch by Duchon and Essenberg (2001). The radar underestimation is relatively less for $\mathrm{N} 2, \mathrm{C} 7$, and C4. All radar QPEs over predicts events 1, 12, 13, and 20, which were taken place in late fall/early winter and could be possibly bright band contaminated. NEXRAD over predictions in spring and fall may also be due to the bright band effect. The discrepancy in sampling heights between KBUF NEXRAD S-band and WKR C-band measurements could be a complicating factor that affects the bias as NEXRAD and WKR radar do not measure the same volume in the space and time. Besides possible errors during radar measurements, the variations in the individual event biases can be attributed to storm type and magnitude (McKee and Binns 2016). The weather radar underestimates precipitation during convective summer events and overestimates stratiform events in late fall/early winter (Kalinga and Gan 2006; McKee and Binns 2016).

Figure 4a shows the radar QPE detection for each station across the basin. For all radar QPEs, the detection is reasonably constant across the basin. As shown in the box plots in Fig. 4b, WKR C-band radar detects all events effectively with low IQR. The detection ranges from $65 \%$ to $85 \%$ for all WKR C-band radar QPEs at each TRCA rain gauge station. The $\mathrm{C} 7$ shows the best average detection of $81.55 \%$ among all the radar QPEs along with the least reported IQR in Fig. 4b. NEXRAD S-band radar detection is relatively small compared to WKR C-band radar. N2 detection $(56.24 \%-68.15 \%)$ is better than N1 (20.31\%-27.37\%). As mentioned before, the detection is affected by the distance to the radar station from the gauge stations. N2 is competitive with WKR C-band radar, whereas N1 shows relatively low detection.

Figure $4 \mathrm{c}$ shows the correlation between the hourly accumulations of radar-gauge pairs for each station across the basin. The average correlation for radar QPEs from KBUF NEXRAD (0.34-0.60) is greater to all C-band radar QPEs (0.20-0.52). The reported average correlation for $\mathrm{N} 2$ of 0.54 is superior to $\mathrm{N} 1(0.44)$. The WKR C-band, C7, and C4 are also competitive with NEXRAD radar QPEs with relatively good reported 


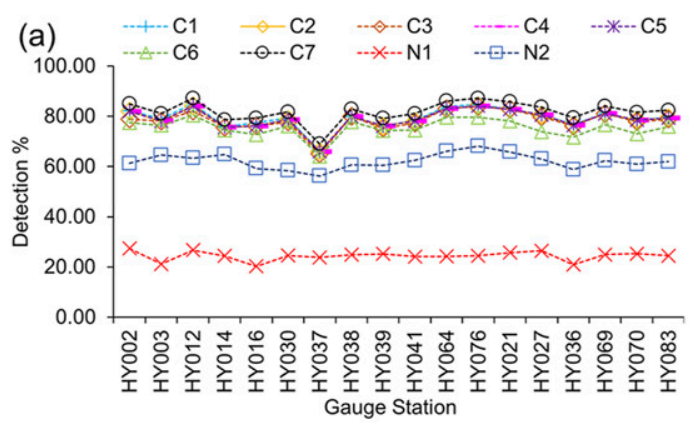

(c)

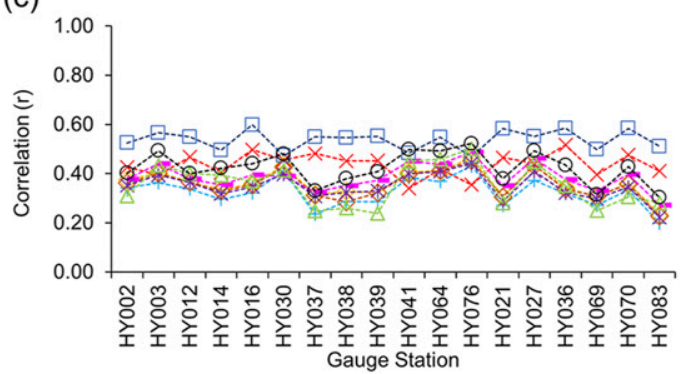

(e)

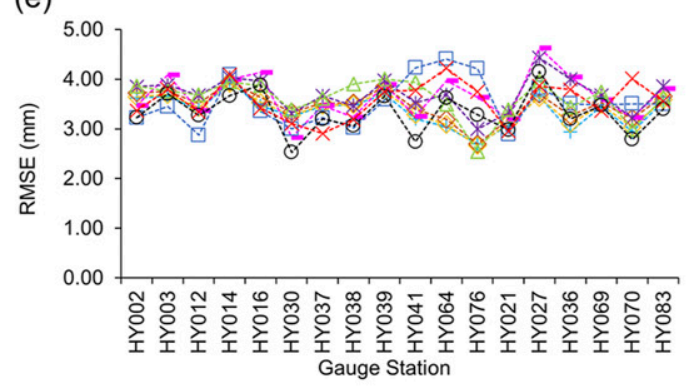

(g)

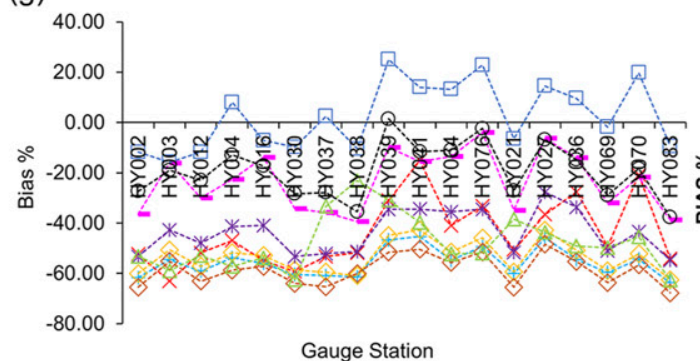

(b) $\square \mathrm{C} 1 \square \mathrm{C} 2 \square \mathrm{C} 3 \square \mathrm{C} 4 \square \mathrm{C} 5 \square \mathrm{C} 6 \square \mathrm{C} 7 \square \mathrm{N} 1 \square \mathrm{N} 2$

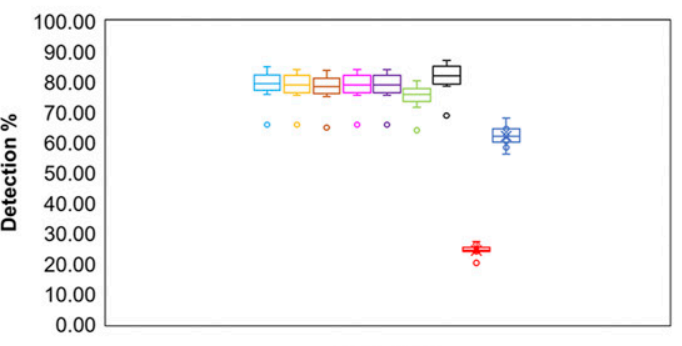

(d)
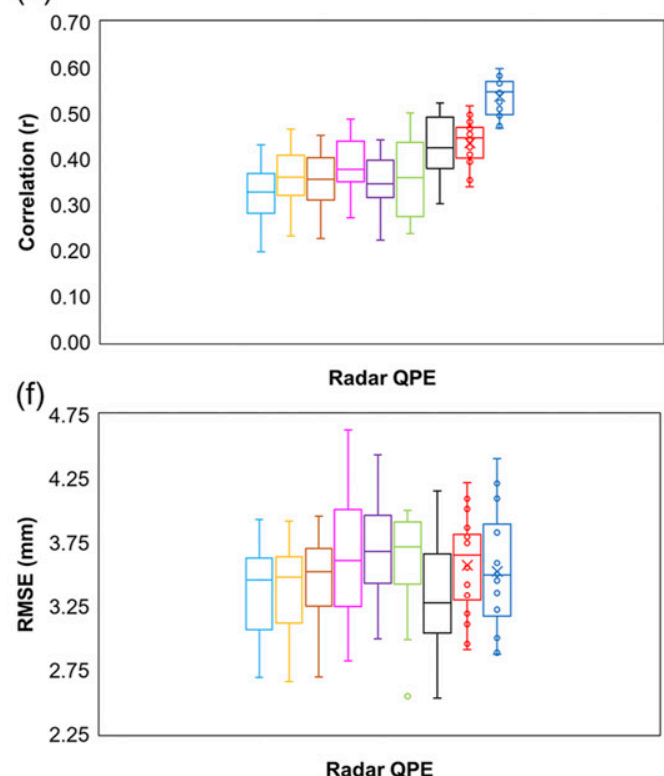

(h)

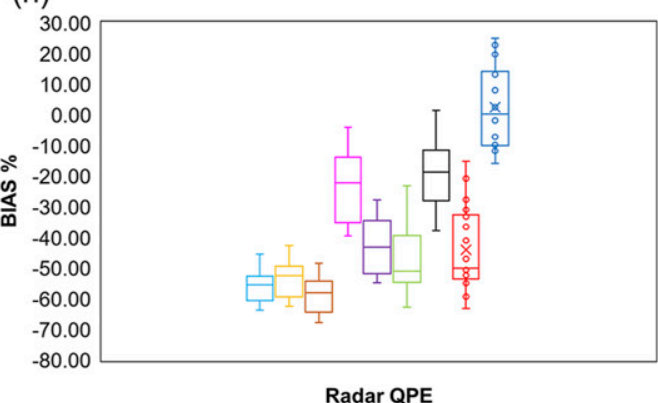

FIG. 4. (a),(b) Average detection, (c),(d) correlation, (e),(f) RMSE, and (g),(h) bias between hourly accumulation of radar QPEs and gauge measurements for each TRCA gauge station.

correlations of 0.42 and 0.40 , respectively. In contrast to events, there is no dramatic variability in correlation for each station across the two watersheds. As shown in Fig. 4d, the correlation does not significantly vary from station to station. Reported IQRs for those QPEs are relatively lower, implying that at all stations, all radar QPEs perform equally well.

As shown in Fig. 4e, the average RMSE between the hourly accumulations of radar-gauge pairs at each gauge stations across the two watersheds approximately ranges from 2.5 to $4.6 \mathrm{~mm}$ and from 2.8 to $4.4 \mathrm{~mm}$ for WKR C-band and KBUF NEXRAD S-band, respectively. Error values are reasonably constant across the basin, and the RMSE follows the same trend as the correlation. The least average error of $2.5 \mathrm{~mm}$ is reported for radar QPE using $\mathrm{C}$, followed by $\mathrm{N} 2$ $(2.6 \mathrm{~mm})$. Since spatial distribution of correlation and errors is constant across the two watersheds, so they can 
(a)

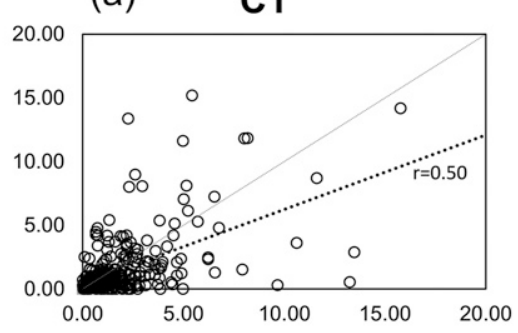

(d)

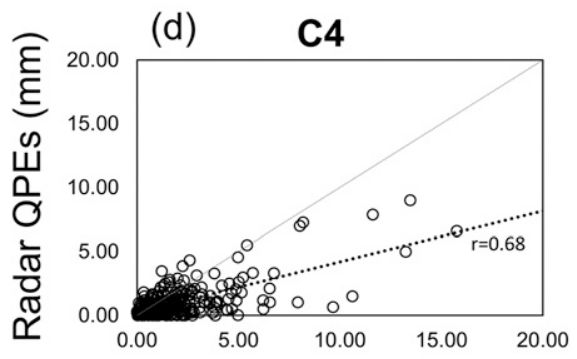

(g)

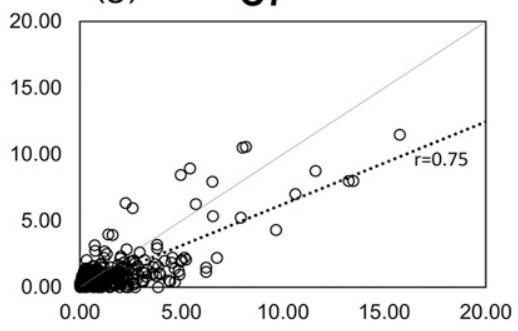

(b)

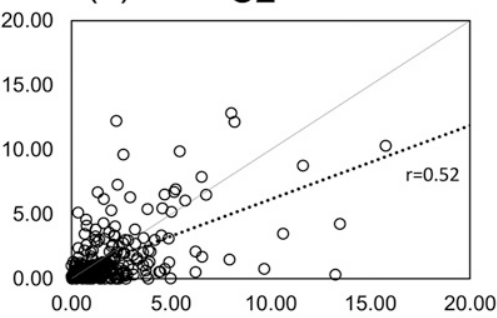

(e) $\quad$ C5

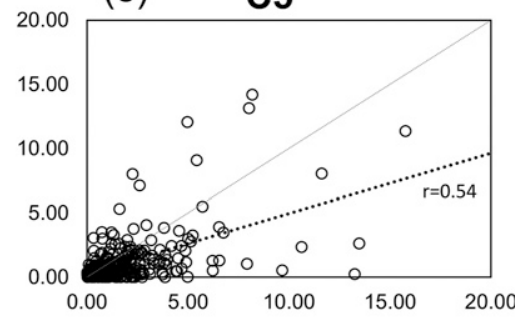

(h)

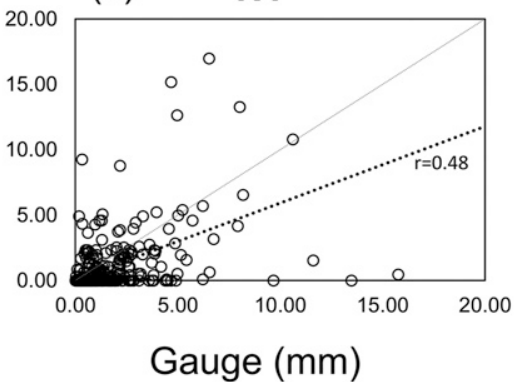

(c)

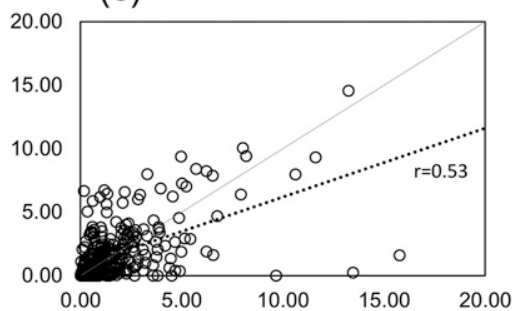

(f) $\quad \mathrm{C6}$

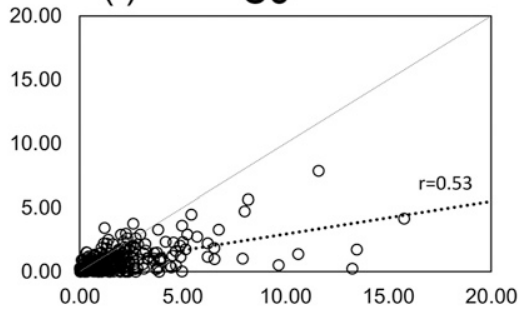

(i) $\quad \mathrm{N} 2$

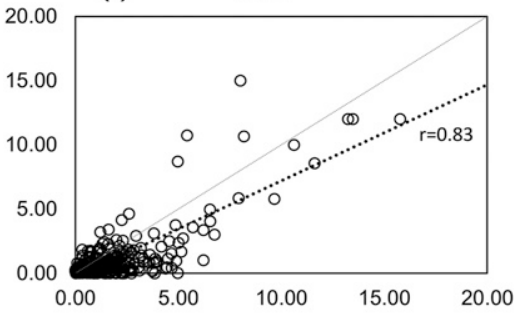

FIG. 5. Scatterplots of hourly accumulations of radar estimated QPEs against the gauge for the radar QPE estimators listed in Table 1.

be used as gridded precipitation input for hydrological models, especially for semi and fully distributed hydrological models. On the other hand, relatively high IQR values of reported RMSEs for all radar QPEs (Fig. 4f) indicate that errors associated with different events at the same station are considerably different.

Figures $4 \mathrm{~g}$ and $4 \mathrm{~h}$ show the distribution of bias values and boxplots over the stations for each radar's QPEs. As shown in Fig. 4g, all radar QPEs are less than the gauge precipitation except for $\mathrm{N} 2$. The bias is fluctuating around the zero line for N2. The underestimation is relatively less for $\mathrm{N} 1$ (from -15.17 to -63.10 ), $\mathrm{C} 7$ (from -37.76 to -1.41 ), and $\mathrm{C} 4$ (from -4.02 to -39.47 ). The reported bias is relatively high for the rest of the C-band (C1, C2, C3, C5, and C6) radar QPEs. Therefore, a correction is necessary before using them as precipitation input for hydrological models. Even though bias values are high, they are consistent with relatively low IQR (Fig. 4h), especially for C1, C2, and C3. The constant bias can be addressed and adjusted during the calibration of hydrological models by incorporating a bias constraint into the objective function (Chiew et al. 2009; Madsen et al. 2002; Viney et al. 2009).

Overall, there is no dramatic variability among matrices across the two watersheds. The reasonably similar matrices across the two watersheds can be attributed to the similar characteristics shared by the two watersheds. A relatively high-density gauge network (one gauge per $\sim 75 \mathrm{~km}^{2}$ in Humber River and one gauge per $\sim 116 \mathrm{~km}^{2}$ in the Don River) with a uniform distribution of gauges across the two basins helps to capture the spatial distribution of rainfall adequately. Also, all gauges are located within $\sim 40$-km radius range of WKR Canadian C-band radar station and $\sim 106-\mathrm{km}$ KBUF NEXRAD S-band radar station. Therefore, the effect of distance (range) from the radar towers to the gauges nearly the same for both watersheds. Hence, the effect of range to radar QPEs is minimal and nearly the same throughout both the two watersheds. As can be seen in Fig. 1, the elevation in most of the area is relatively similar and, thus, no high barriers that hinder the radar signals affecting radar reflectivities and, subsequently, the radar 


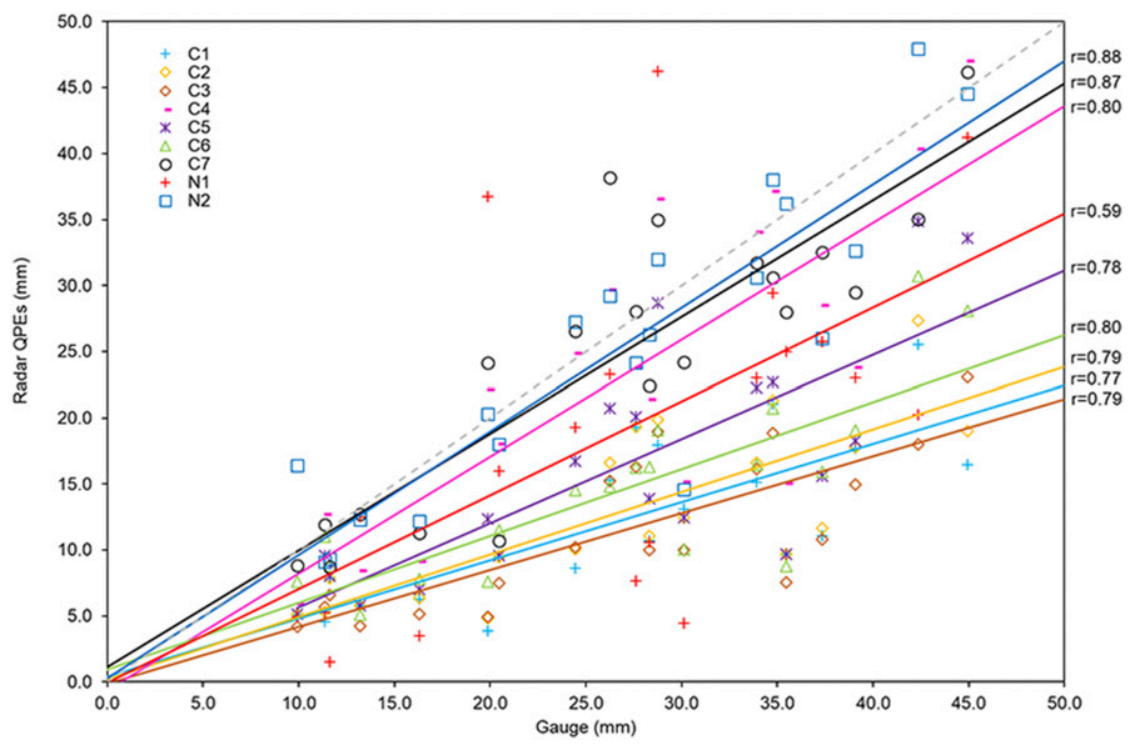

FIG. 6. Scatterplots of radar estimated totals against the gauge totals for 20 events.

QPEs. The C-band radar station is located in an elevated area and therefore provides better coverage for both watersheds. As the region seen by the both WKR C-band and NEXRAD S-band radar shares similar characteristics, the observed constant errors and correlations between gauges and radar QPEs is reasonable.

To further assess the radar QPE performances, scatterplots between the hourly accumulations of $\operatorname{radar}(R)$ gauge $(G)$ pairs for all events (i.e., for the $297 \mathrm{~h}$ ) for each radar QPE are shown in Fig. 5. The solid line in the figure represents the one-to-one line. The dotted lines in the figure represent the least absolute deviation fits for the form of $R=a G+b$ for the hourly radar-gauge pairs for all events. The $R(Z), R\left(Z, K_{\mathrm{DP}}\right), R\left(Z, Z_{\mathrm{DR}}\right)$, and $R\left(K_{\mathrm{DP}}, Z_{\mathrm{DR}}\right)$ radar QPEs with and without attenuation correction of WKR C-band radar and KBUF NEXRAD S-band radar are shown in Fig. 5. For all radar QPEs, the best fit line is well below one, except for the $\mathrm{C} 7$ and $\mathrm{N}$ 2. The average correlation coefficient reported for the $\mathrm{C} 7$ and N2 is 0.60 and 0.71 , respectively. Average RMSE reported as 3.2 and $2.8 \mathrm{~mm}$ for $\mathrm{C} 7$ and $\mathrm{N} 2$, respectively. Data are also more clustered along the one-to-one line, and $\mathrm{C} 7$ and $\mathrm{N} 2$ radar QPEs generally perform well compared to the gauge observation. Those two radar QPEs perform reasonably well for most of the accumulations except for underestimation at lower accumulation amounts. Both $\mathrm{C} 7$ and $\mathrm{N} 2$ perform reasonably well for higher accumulation amounts. All other QPEs show some inconsistencies at the medium and higher accumulations. The scatterplots also show that the results are more dispersed from the one-to-one line with the increasing accumulations for all the radar QPEs.
In general, the $\mathrm{C} 7$ and the $\mathrm{N} 2$ show better agreement with the gauges for all accumulation amounts.

Hourly accumulation of precipitation values is summed for each radar QPE and each event to produce radar totals $R_{T}$ to compare with gauge totals $G_{T}$. A scatterplot of the gauge totals against radar totals is shown in Fig. 6. The solid line in the figure represents the least absolute deviation fits for the form of $R_{T}=a G_{T}+$ $b$ for the 20 event totals. The dashed line is the one-toone line. In contrast to the high degree of scattering between radar QPEs and gauge reported precipitation for hourly data (Fig. 5), the event totals graphed in Fig. 6 show a definite linear relationship, but less scatter in the longer-term radar estimates. The spread between all radar QPEs and gauge observations decreases with more extended temporal accumulation. For example, the correlation coefficient increases from hourly to event total of $0.63-0.76$ for N2. Reduction in the spatial variability of the rainfall field due to time averaging minimizes the inconsistencies in radar and gauge sampling areas.

The radar-gauge ratios are calculated for the hourly rainfall accumulations estimated by each rain-rate algorithms for the $297 \mathrm{~h}$ of analysis (i.e., all events) and plotted (Fig. 7) as a function of the gauge hourly accumulations to illustrate the relative strengths of each algorithm at high and low rain rates. The ratio of one indicates unbiased radar estimates. For hourly accumulations, the ratios are much less or higher than one for all radar QPEs for lower precipitation amounts ranging from 1 to $5 \mathrm{~mm}$. However, the ratio has become progressively better with higher precipitation amounts, 
(a)

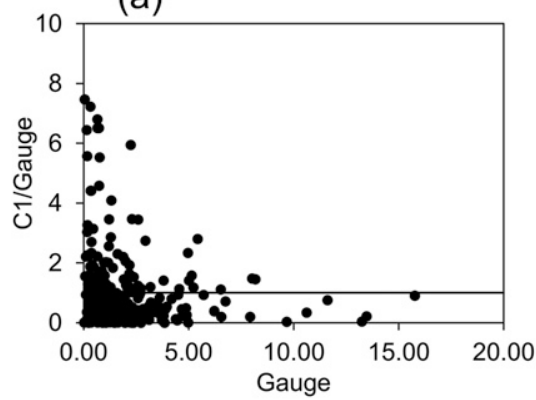

(d)

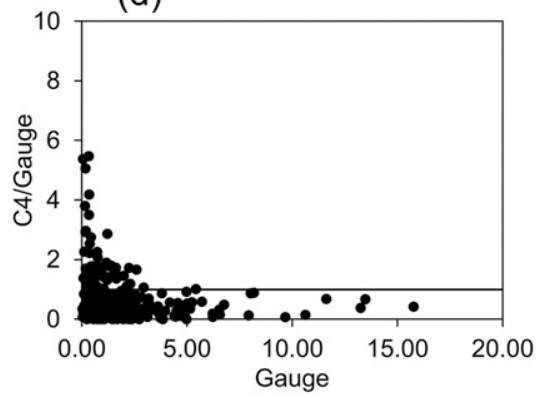

(g)

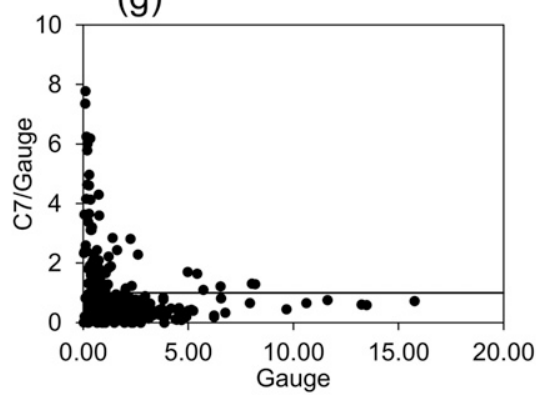

(b)

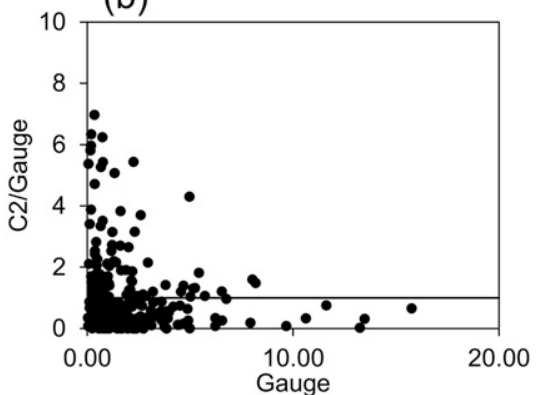

(e)

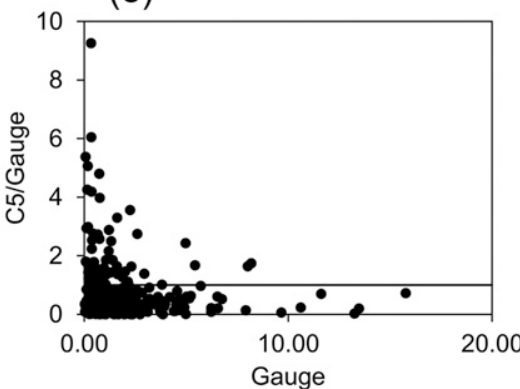

(h)

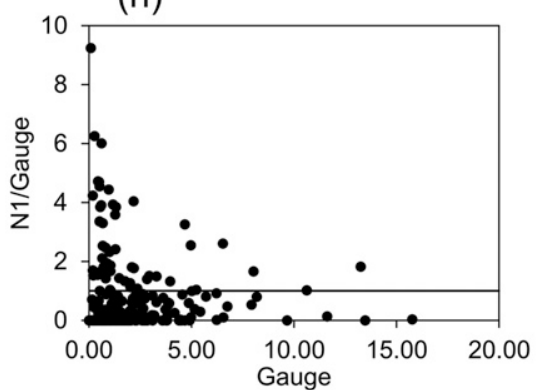

(c)

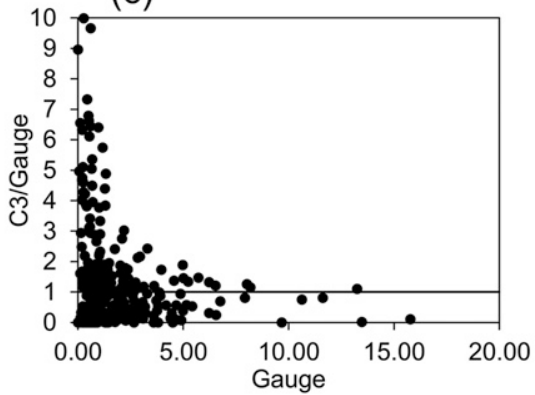

(f)

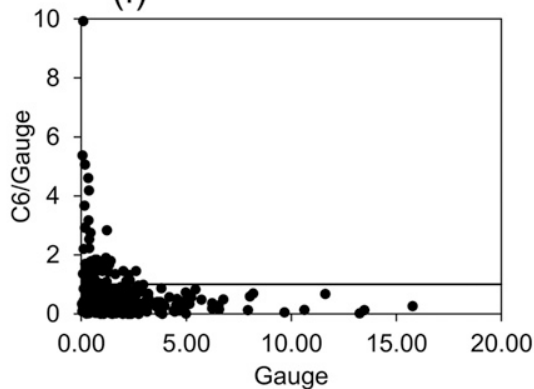

(i)

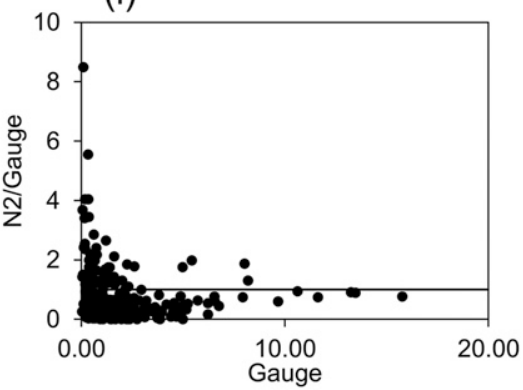

FIG. 7. Ratios of radar-gauge hourly accumulations as a function of the hourly gauge accumulations for the radar QPE estimators listed in Table 1.

especially for $\mathrm{C} 7$ and $\mathrm{N} 2$. Both $\mathrm{C} 7$ and $\mathrm{N} 2$ have ratios much closer to one for high hourly gauge accumulation amounts from 10 to $15 \mathrm{~mm}$.

For further analysis, Taylor diagrams are drawn to select the best performing radar QPE based on three statistical parameters: standard deviation, correlation coefficient, and centered root-mean-square error for both hourly accumulations for $297 \mathrm{~h}$ (Fig. 8a) and total event accumulations (Fig. 8b). Comparable to the results discussed above, the N2, C7, and C4 QPEs perform comparatively well as they are plotted closest to the black arc as well as the point observation ("OBS" in the figure).

\section{Conclusions}

In this study, radar-derived QPEs from rain-rate relationships using $Z, Z_{\mathrm{DR}}$, and $K_{\mathrm{DP}}$ from WKR C-band radar at King City, Ontario, Canada, and the QPEs from
NEXRAD S-band radar at Buffalo, New York, United States, are evaluated against rain gauge data for two watersheds in the GTA of Ontario, Canada: Humber River (semiurban) and Don River (urban) watersheds. The objective is to assess the reliability and accuracy of WKR and NEXRAD radar QPEs as precipitation input of hydrological models for hydrometeorological applications.

Relatively high percent detection, high correlation, low RMSE, and small percent bias suggest that the KBUF NEXRAD radar QPEs can be effectively used as supplementary precipitation forcing for hydrological models in Canadian watersheds that are covered by the U.S. radar. The WKR radar QPEs utilizing a multiparameter rain rate estimator using $K_{\mathrm{DP}}$ and $Z_{\mathrm{DR}}$ performs equally as KBUF NEXRAD radar QPEs. Due to the high temporal resolution, a long-term data archive, and good percent detection of WKR radar QPEs, it is possible to generate a continuous time series with a 
(a)

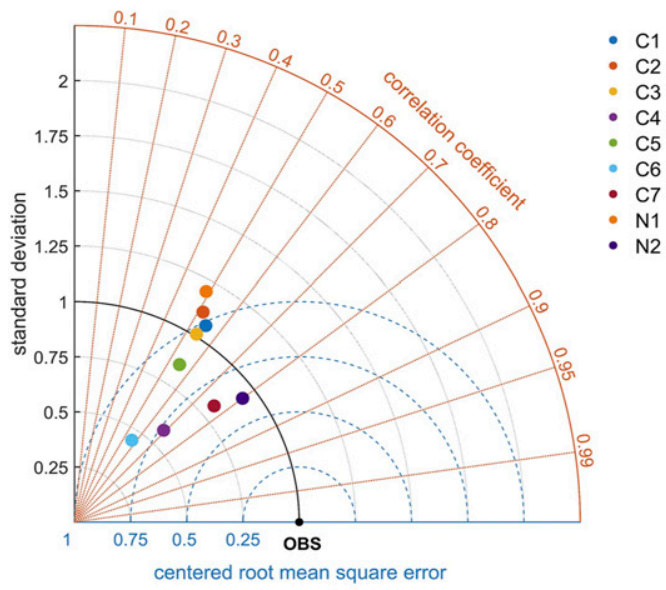

(b)

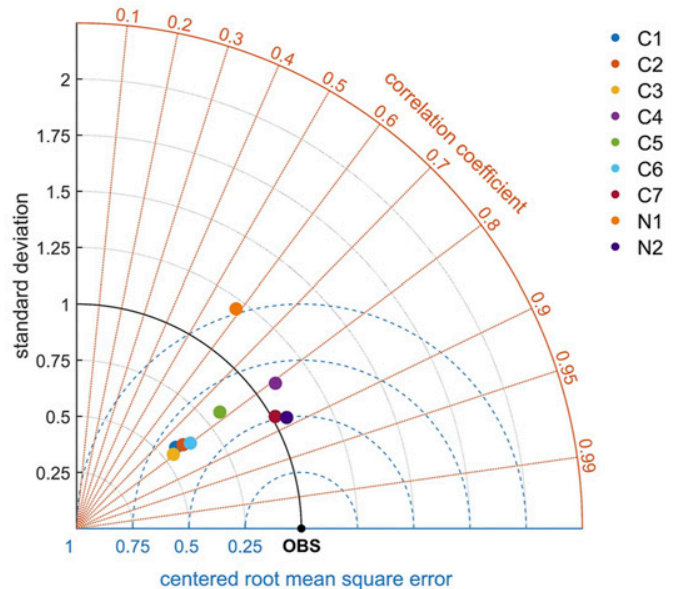

FIG. 8. Taylor diagrams showing a statistical assessment of radar estimated QPEs listed in Table 1 for hourly accumulations for (a) $297 \mathrm{~h}$ and (b) total event accumulations. [Note that the diagram summarizes three statistical performances (standard deviation, correlation coefficient, and centered root-mean-square error) for each radar QPE. Different colors denote different radar QPEs. The best radar QPE plots itself closer to the black arc as well as the point OBS, which represents agreement with gauge observations.]

smaller number of missing data that is often required as meteorological input for hydrological models. Therefore, WKR radar QPEs with dual-polarization algorithms can also effectively be used as precipitation input of the hydrological model for hydrometeorological applications. Because of the closeness of the watershed to the WKR radar station, it may be preferable. Spatial variations in all verification matrices are reasonably constant across the basins and, hence, can be used as a gridded precipitation input of distributed hydrological models.

Among nine radar QPEs used in this evaluation, NEXRAD Level III (DPA), WKR multiparameter rain rate estimator using $K_{\mathrm{DP}}$ and $Z_{\mathrm{DR}}$, and combined $Z$ and $K_{\mathrm{DP}}$ algorithm are chosen for further studies. Since verification matrices are not optimum for both WKR radar and KBUF NEXRAD radar QPEs, bias correction is necessary before using selected radar QPEs as a precipitation input to hydrological models. In the future, this evaluation will be followed by proxy validation with the event-based hydrological model run using semidistributed and distributed hydrological models to further verify the accuracy and reliability of the radar QPE as precipitation input of hydrological models for hydrometeorological applications.

Acknowledgments. This work was funded by the Natural Science and Engineering Research Council (NSERC) Canadian FloodNet (NETGP 451456). The task for this manuscript was performed while the first author, Dayal Buddika Wijayarathne, was an intern graduate student at Observations-Based Research Section, ECCC.
Hourly rain gauge measurements were collected from Toronto and Region Conservation Authority (TRCA; https://trca.ca/). The KBUF NEXRAD S-band radar QPEs were downloaded from the NOAA National Centers for Environmental Information website: https://www.ncdc.noaa.gov/has/HAS.FileAppRouter? datasetname $=7000 \&$ subqueryby $=$ STATION \&applname $=$ \&outdest $=$ FILE. The open-source software tool kit NOAA's WCT downloaded from the website: https://www.ncdc.noaa.gov/wct/ was used to process NEXRAD radar QPEs. The authors thank Mr. Andre D.L. Zanchetta for his help in downloading and preprocessing NEXRAD data. The authors declare no conflict of interest.

\section{REFERENCES}

Austin, P. M., and A. C. Bemis, 1950: A quantitative study of the "bright band" in radar precipitation echoes. J. Meteor., 7, 145-151, https://doi.org/10.1175/1520-0469(1950)007<0145: $\mathrm{AQSOTB}>2.0 . \mathrm{CO} ; 2$.

Ayat, H., M. R. Kavianpour, S. Moazami, Y. Hong, and E. Ghaemi, 2018: Calibration of weather radar using Region Probability Matching Method (RPMM). Theor. Appl. Climatol., 134, 165-176, https://doi.org/10.1007/s00704-017-2266-7.

Aydin, K., V. N. Bringi, and L. Liu, 1995: Rain-rate estimation in the presence of hail using S-band specific differential phase and other radar parameters. J. Appl. Meteor., 34, 404-410, https://doi.org/10.1175/1520-0450-34.2.404.

Balica, S. F., I. Popescu, L. Beevers, and N. G. Wright, 2013: Parametric and physically based modelling techniques for flood risk and vulnerability assessment: A comparison. Environ. Modell. Software, 41, 84-92, https://doi.org/10.1016/ j.envsoft.2012.11.002. 
Barge, B. L., R. G. Humphries, S. J. Mah, and W. K. Kuhnke, 1979: Rainfall measurements by weather radar: Applications to hydrology. Water Resour. Res., 15, 1380-1386, https://doi.org/ 10.1029/WR015i006p01380.

Beneti, C., R. V. Calheiros, M. Sorribas, L. Calvetti, C. Oliveira, N. Rozin, and J. Ruviaro, 2019: Operational hydrological modelling of small watershed using QPE from dual-pol radar in Brazil. Preprints, 2019060026, https://doi.org/10.20944/ preprints201906.0026.v1.

Berkowitz, D. S., J. A. Schultz, S. Vasiloff, K. L. Elmore, C. D. Payne, and J. B. Boettcher, 2013: Status of dual pol QPE in the WSR-88D network. 27th Conf. on Hydrology, Austin, TX, Amer. Meteor. Soc., 2.2, https://ams.confex.com/ams/93Annual/ webprogram/Paper221525.html.

Boluwade, A., K.-Y. Zhao, T. A. Stadnyk, and P. Rasmussen, 2018: Towards validation of the Canadian Precipitation Analysis (CaPA) for hydrologic modeling applications in the Canadian prairies. J. Hydrol., 556, 1244-1255, https://doi.org/10.1016/ j.jhydrol.2017.05.059.

Boodoo, S., D. Hudak, A. Ryzhkov, P. Zhang, N. Donaldson, D. Sills, and J. Reid, 2015: Quantitative precipitation estimation from a C-band dual-polarized radar for the 8 July 2013 flood in Toronto, Canada. J. Hydrometeor., 16, 2027-2044, https://doi.org/10.1175/JHM-D-15-0003.1.

Borga, M., F. Tonelli, R. J. Moore, and H. Andrieu, 2002: Longterm assessment of bias adjustment in radar rainfall estimation. Water Resour. Res., 38, 1266, https://doi.org/10.1029/ 2001 WR000555.

Bowering, E. A., A. M. Peck, and S. P. Simonovic, 2014: A flood risk assessment to municipal infrastructure due to changing climate part I: Methodology. Urban Water J., 11, 20-30, https:// doi.org/10.1080/1573062X.2012.758293.

Brandes, E. A., A. V. Ryzhkov, and D. S. Zrnić, 2001: An evaluation of radar rainfall estimates from specific differential phase. J. Atmos. Oceanic Technol., 18,363-375, https://doi.org/10.1175/ 1520-0426(2001)018<0363:AEORRE > 2.0.CO;2.

-, G. Zhang, and J. Vivekanandan, 2002: Experiments in rainfall estimation with a polarimetric radar in a subtropical environment. J. Appl. Meteor., 41, 674-685, https://doi.org/ 10.1175/1520-0450(2002)041<0674:EIREWA > 2.0.CO;2.

Bringi, V. N., M. A. Rico-Ramirez, and M. Thurai, 2011: Rainfall estimation with an operational polarimetric C-band radar in the United Kingdom: Comparison with a gauge network and error analysis. J. Hydrometeor., 12, 935-954, https://doi.org/ 10.1175/JHM-D-10-05013.1.

Chandrasekar, V., R. Keränen, S. Lim, and D. Moisseev, 2013: Recent advances in classification of observations from dual polarization weather radars. Atmos. Res., 119, 97-111, https:// doi.org/10.1016/j.atmosres.2011.08.014.

Chen, D., and A. Farrar, 2007: Evaluation of NARAD precipitation data for rainfall monitoring in eastern Ontario, Canada. Geomatics Solutions for Disaster Management, J. Li, S. Zlatanova, and A. G. Fabbri, Eds., Lecture Notes in Geoinformation and Cartography, Springer, 103-116, https://doi.org/10.1007/978-3-540-72108-6_8.

Chiew, F. H. S., J. Teng, J. Vaze, D. A. Post, J. M. Perraud, D. G. C. Kirono, and N. R. Viney, 2009: Estimating climate change impact on runoff across southeast Australia: Method, results, and implications of the modeling method. Water Resour. Res., 45, W10414, https://doi.org/10.1029/2008WR007338.

Cloke, H. L., and F. Pappenberger, 2009: Ensemble flood forecasting: A review. J. Hydrol., 375, 613-626, https://doi.org/ 10.1016/j.jhydrol.2009.06.005.
Crozier, C. L., P. I. Joe, J. W. Scott, H. N. Herscovitch, and T. R. Nichols, 1991: The king city operational Doppler radar: Development, all-season applications and forecasting. Atmos.-Ocean, 29, 479-516, https://doi.org/10.1080/07055900.1991.9649414.

Dai, Q., Q. Yang, J. Zhang, and S. Zhang, 2018: Impact of gauge representative error on a radar rainfall uncertainty model. J. Appl. Meteor. Climatol., 57, 2769-2787, https://doi.org/10.1175/ JAMC-D-17-0272.1.

Dalezios, N. R., 1988: Objective rainfall evaluation in radar hydrology. J. Water Resour. Plann. Manage., 114, 531-546, https://doi.org/ 10.1061/(ASCE)0733-9496(1988)114:5(531).

Damant, C., G. L. Austin, A. Bellon, M. Osseyrane, and N. Nguyen, 1983: Radar rain forecasting for wastewater control. J. Hydraul. Eng., 109, 293-297, https://doi.org/10.1061/(ASCE)07339429(1983)109:2(293).

Dhiram, K., and Z. Wang, 2016: Evaluation on radar reflectivityrainfall rate (Z-R) relationships for Guyana. Atmos. Climate Sci., 6, 489-499, https://doi.org/10.4236/ACS.2016.64039.

Diakakis, M., G. Deligiannakis, A. Pallikarakis, and M. Skordoulis, 2016: Factors controlling the spatial distribution of flash flooding in the complex environment of a metropolitan urban area. The case of Athens 2013 flash flood event. Int. J. Disaster Risk Reduct., 18, 171-180, https://doi.org/10.1016/j.ijdrr.2016.06.010.

Douglas, R. H., 1990: The stormy weather group (Canada). Radar in Meteorology, D. Atlas, Ed., Springer, 61-68, https://doi.org/ 10.1007/978-1-935704-15-7_8.

Duchon, C. E., and G. R. Essenberg, 2001: Comparative rainfall observations from pit and aboveground rain gauges with and without wind shields. Water Resour. Res., 37, 3253-3263, https://doi.org/10.1029/2001WR000541.

Dufton, D. R. L., 2016: Quantifying uncertainty in radar rainfall estimates using an X-band dual polarisation weather radar. Ph.D. dissertation, University of Leeds, $229 \mathrm{pp}$.

Einfalt, T., K. Arnbjerg-Nielsen, C. Golz, N.-E. Jensen, M. Quirmbach, G. Vaes, and B. Vieux, 2004: Towards a roadmap for use of radar rainfall data in urban drainage. J. Hydrol., 299, 186202, https://doi.org/10.1016/S0022-1694(04)00365-8.

Fabry, F., and I. Zawadzki, 1995: Long-term radar observations of the melting layer of precipitation and their interpretation. J. Atmos. Sci., 52, 838-851, https://doi.org/10.1175/15200469(1995)052<0838:LTROOT>2.0.CO;2.

Fassnacht, S. R., 2003: Radar precipitation for winter hydrological. IAHS Publ., 282, 35-42, https://iahs.info/uploads/dms/iahs_ 282_035.pdf.

Fortin, V., G. Roy, N. Donaldson, and A. Mahidjiba, 2015: Assimilation of radar quantitative precipitation estimations in the Canadian Precipitation Analysis (CaPA). J. Hydrol., 531, 296-307, https://doi.org/10.1016/j.jhydrol.2015.08.003.

Fulton, R. A., J. P. Breidenbach, D.-J. Seo, D. A. Miller, and T. O'Bannon, 1998: The WSR-88D rainfall algorithm. Wea. Forecasting, 13, 377-395, https://doi.org/10.1175/1520-0434(1998) $013<0377$ :TWRA $>2.0 . \mathrm{CO} ; 2$.

Germann, U., 1999: Radome attenuation-A serious limiting factor for quantitative radar measurements? Meteor. Z., 8, 85-90, https://doi.org/10.1127/metz/8/1999/85.

Grayman, W. M., and P. S. Eagleson, 1971: Evaluation of radar and raingage systems for flood forecasting. Ralph M. Parsons Laboratory Tech. Rep. 138, Massachusetts Institute of Technology, 324 pp.

Guzman, J. A., D. N. Moriasi, M. L. Chu, P. J. Starks, J. L. Steiner, and P. H. Gowda, 2013: A tool for mapping and spatio-temporal analysis of hydrological data. Environ. Modell. Software, 48, 163-170, https://doi.org/10.1016/j.envsoft.2013.06.014. 
Hall, W., M. A. Rico-Ramirez, and S. Krämer, 2015: Classification and correction of the bright band using an operational C-band polarimetric radar. J. Hydrol., 531, 248-258, https://doi.org/ 10.1016/j.jhydrol.2015.06.011.

Han, S., and P. Coulibaly, 2017: Bayesian flood forecasting methods: A review. J. Hydrol., 551, 340-351, https://doi.org/ 10.1016/j.jhydrol.2017.06.004.

Hapuarachchi, H. A. P., Q. J. Wang, and T. C. Pagano, 2011: A review of advances in flash flood forecasting. Hydrol. Processes, 25, 2771-2784, https://doi.org/10.1002/hyp.8040.

Hubbert, J. C., M. Dixon, S. M. Ellis, and G. Meymaris, 2009: Weather radar ground clutter. Part I: Identification, modeling, and simulation. J. Atmos. Oceanic Technol., 26, 1165-1180, https://doi.org/10.1175/2009JTECHA1159.1.

Jentsch, A., J. Kreyling, and C. Beierkuhnlein, 2007: A new generation of climate-change experiments: Events, not trends. Front. Ecol. Environ., 5, 365-374, https://doi.org/10.1890/15409295(2007)5[365:ANGOCE]2.0.CO;2.

Joe, P., and S. Lapczak, 2002: Evolution of the Canadian operational radar network. Proceedings of ERAD (2002), Copernicus, 370-382.

Kalinga, O. A., and T. Y. Gan, 2006: Semi-distributed modelling of basin hydrology with radar and gauged precipitation. Hydrol. Processes, 20, 3725-3746, https://doi.org/10.1002/ hyp.6385.

Khan, S. I., Z. Flamig, and Y. Hong, 2019: Flood monitoring system using distributed hydrologic modeling for Indus River Basin. Indus River Basin, Elsevier, 335-355, https://doi.org/10.1016/ b978-0-12-812782-7.00015-1.

Krajewski, W. F., and Coauthors, 2010a: Towards better utilization of NEXRAD data in hydrology: An overview of HydroNEXRAD. J. Hydroinform., 13, 255-266, https://doi.org/ 10.2166/hydro.2010.056.

_ , G. Villarini, and J. A. Smith, 2010b: Radar-rainfall uncertainties: Where are we after thirty years of effort? Bull. Amer. Meteor. Soc., 91, 87-94, https://doi.org/10.1175/2009BAMS2747.1.

_ mation system for the state of Iowa. Bull. Amer. Meteor. Soc. 98, 539-554, https://doi.org/10.1175/BAMS-D-15-00243.1.

Lack, S. A., and N. I. Fox, 2007: An examination of the effect of winddrift on radar-derived surface rainfall estimations. Atmos. Res. 85, 217-229, https://doi.org/10.1016/j.atmosres.2006.09.010.

Madsen, H., G. Wilson, and H. C. Ammentorp, 2002: Comparison of different automated strategies for calibration of rainfallrunoff models. J. Hydrol., 261, 48-59, https://doi.org/10.1016/ S0022-1694(01)00619-9.

Maki, M., S.-G. Park, and V. N. Bringi, 2005: Effect of natural variations in rain drop size distributions on rain rate estimators of $3 \mathrm{~cm}$ wavelength polarimetric radar. J. Meteor. Soc. Japan, 83, 871-893, https://doi.org/10.2151/jmsj.83.871.

Marshall, J. S., and W. M. K. Palmer, 1948: The distribution of raindrops with size. J. Meteor., 5, 165-166, https://doi.org/ 10.1175/1520-0469(1948)005<0165:TDORWS > 2.0.CO;2.

Marx, A., H. Kunstmann, A. Bárdossy, and J. Seltmann, 2006: Radar rainfall estimates in an alpine environment using inverse hydrological modelling. Adv. Geosci., 9, 25-29, https:// doi.org/10.5194/adgeo-9-25-2006.

Mazzarella, V., I. Maiello, R. Ferretti, V. Capozzi, E. Picciotti, P. P. Alberoni, F. S. Marzano, and G. Budillon, 2020: Reflectivity and velocity radar data assimilation for two flash flood events in central Italy: A comparison between 3D and 4D variational methods. Quart. J. Roy. Meteor. Soc., 146, 348-366, https:// doi.org/10.1002/qj.3679.
McKee, J. L., and A. D. Binns, 2016: A review of gauge-radar merging methods for quantitative precipitation estimation in hydrology. Can. Water Resour. J., 41, 186-203, https://doi.org/ 10.1080/07011784.2015.1064786.

Meischner, P., 2005: Weather Radar: Principles and Advanced Applications. Springer, $315 \mathrm{pp}$.

Mekis, E., N. Donaldson, J. Reid, A. Zucconi, J. Hoover, Q. Li, R. Nitu, and S. Melo, 2018: An overview of surface-based precipitation observations at environment and climate change Canada. Atmos.-Ocean, 56, 71-95, https://doi.org/10.1080/ 07055900.2018.1433627.

Mekonnen, G. B., S. Matula, F. Doležal, and J. Fišák, 2015: Adjustment to rainfall measurement undercatch with a tipping-bucket rain gauge using ground-level manual gauges. Meteor. Atmos. Phys., 127, 241-256, https://doi.org/10.1007/s00703-014-0355-z.

Moore, R. J., A. E. Jones, D. A. Jones, K. B. Black, and V. A. Bell, 2004: Weather radar for flood forecasting: Some UK experiences. Sixth Int. Symp. on Hydrological Applications of Weather Radar, Melbourne, Australia, Bureau of Meteorology, 11 pp.

Moradkhani, H., and S. Sorooshian, 2008: General review of rainfall-runoff modeling: Model calibration, data assimilation, and uncertainty analysis, Hydrological Modelling and the Water Cycle, S. Sorooshian et al., Eds., Water Science and Technology Library, Vol 63, Springer, 1-24, https://doi.org/ 10.1007/978-3-540-77843-1_1.

Natural Resources Canada, 2009: Canadian Land Cover, circa 2000 (Vector) - GeoBase Series - ARCHIVED. Accessed 26 November 2019, https://open.canada.ca/data/dataset/ 97126362-5a85-4fe0-9dc2-915464cfdbb7?activity_id=b4aec57fc9b4-4543-84c0-7401c70fe52c.

Nerini, D., Z. Zulkafli, L. P. Wang, C. Onof, W. Buytaert, W. Lavado-Casimiro, and J. L. Guyot, 2015: A comparative analysis of TRMM-rain gauge data merging techniques at the daily time scale for distributed rainfall-runoff modeling applications. J. Hydrometeor., 16, 2153-2168, https://doi.org/ 10.1175/JHM-D-14-0197.1.

NOAA, 2018: NEXRAD Data Archive, Inventory and Access. Accessed 1 June 2019, https://www.ncdc.noaa.gov/nexradinv/.

Pachauri, R. K., and Coauthors, 2014: Climate Change 2014: Synthesis Report. IPCC, 168 pp.

Park, S. G., V. N. Bringi, V. Chandrasekar, M. Maki, and K. Iwanami, 2005: Correction of radar reflectivity and differential reflectivity for rain attenuation at $\mathrm{X}$ band. Part I: Theoretical and empirical basis. J. Atmos. Oceanic Technol., 22, 1621-1632, https://doi.org/10.1175/JTECH1803.1.

P. C., S., M. Maki, S. Shimizu, T. Maesaka, D.-S. Kim, D.-I. Lee, and H. Iida, 2013: Correction of reflectivity in the presence of partial beam blockage over a mountainous region using X-band dual polarization radar. J. Hydrometeor., 14, 744-764, https://doi.org/10.1175/JHM-D-12-077.1.

Prat, O. P., and B. R. Nelson, 2015: Evaluation of precipitation estimates over CONUS derived from satellite, radar, and rain gauge data sets at daily to annual scales (2002-2012). Hydrol. Earth Syst. Sci., 19, 2037-2056, https://doi.org/10.5194/hess-192037-2015https://doi.org/10.5194/HESSD-11-11489-2014.

Price, K., S. T. Purucker, S. R. Kraemer, J. E. Babendreier, and C. D. Knightes, 2014: Comparison of radar and gauge precipitation data in watershed models across varying spatial and temporal scales. Hydrol. Processes, 28, 3505-3520, https:// doi.org/10.1002/hyp.9890.

Public Safety Canada, 2019: The Canadian Disaster Database. Accessed 13 May 2020, https://www.publicsafety.gc.ca/cnt/ rsrcs/cndn-dsstr-dtbs/index-en.aspx. 
Rabiei, E., and U. Haberlandt, 2015: Applying bias correction for merging rain gauge and radar data. J. Hydrol., 522, 544-557, https://doi.org/10.1016/j.jhydrol.2015.01.020.

Ran, Q., W. Fu, Y. Liu, T. Li, K. Shi, and B. Sivakumar, 2018: Evaluation of quantitative precipitation predictions by ECMWF, CMA, and UKMO for flood forecasting: Application to two basins in China. Nat. Hazards Rev., 19, 05018003, https://oi.org/ 10.1061/(ASCE)NH.1527-6996.0000282.

Reggiani, P., and A. H. Weerts, 2008: A Bayesian approach to decision-making under uncertainty: An application to realtime forecasting in the river Rhine. J. Hydrol., 356, 56-69, https://doi.org/10.1016/j.jhydrol.2008.03.027.

Richards, W. G., and C. L. Crozier, 1983: Precipitation measurement with a C-band weather radar in southern Ontario. Atmos.-Ocean, 21, 125-137, https://doi.org/10.1080/07055900.1983.9649160.

Ryzhkov, A. V., S. E. Giangrande, V. M. Melnikov, and T. J. Schuur, 2005: Calibration issues of dual-polarization radar measurements. J. Atmos. Oceanic Technol., 22, 1138-1155, https://doi.org/10.1175/JTECH1772.1.

- D. Hudak, and J. Scott, 2006: A new polarimetric scheme for attenuation correction at $\mathrm{C}$ band. Proc. Fourth European Conf. on Radar in Meteorology and Hydrology, Barcelona, Spain, GRAHI-UPC, 29-32, http://www.crahi.upc.edu/ ERAD2006/proceedingsMask/00008.pdf.

— , P. Zhang, D. Hudak, J. Alford, M. Knight, and J. Conway, 2007: Validation of polarimetric methods for attenuation correction at C band. Proc. 33rd Conf. on Radar Meteorology, Cairns, Australia, Amer. Meteor. Soc., P11B.12, http://ams.confex.com/ ams/pdfpapers/123122.pdf.

-, M. Diederich, P. Zhang, and C. Simmer, 2014: Potential utilization of specific attenuation for rainfall estimation, mitigation of partial beam blockage, and radar networking. J. Atmos. Oceanic Technol., 31, 599-619, https://doi.org/ 10.1175/JTECH-D-13-00038.1.

Sachidananda, M., and D. S. Zrnić, 1987: Rain rate estimates from differential polarization measurements. J. Atmos. Oceanic Technol., 4, 588-598, https://doi.org/10.1175/1520-0426(1987) $004<0588$ :RREFDP $>2.0$. CO;2.

Schell, G. S., C. A. Madramootoo, G. L. Austin, and R. S. Broughton, 1992: Use of radar measured rainfall for hydrologic modelling. Can. Agric. Eng., 34, 41-48.

Şensoy, A., G. Uysal, and A. A. Şorman, 2016: Developing a decision support framework for real-time flood management using integrated models. J. Flood Risk Manag., 11, S866-S883, https://doi.org/10.1111/jfr3.12280.

Seo, D. J., E. Habib, H. Andrieu, and E. Morin, 2015: Hydrologic applications of weather radar. J. Hydrol., 531, 231-233, https:// doi.org/10.1016/j.jhydrol.2015.11.010.

Sevruk, B., 1982: Methods of correction for systematic error in point precipitation measurement for operational use. Operational Hydrology Rep. 21, WMO Rep. 589, 91 pp., https:// library.wmo.int/doc_num.php?explnum_id=1238.

Sills, D. M., and P. I. Joe, 2019: From pioneers to practitioners: A short history of severe thunderstorm research and forecasting in Canada. Atmos.-Ocean, 57, 249-261, https://doi.org/ 10.1080/07055900.2019.1673145.

Stellman, K. M., H. E. Fuelberg, R. Garza, and M. Mullusky, 2001: An examination of radar and rain gauge-derived mean areal precipitation over Georgia watersheds. Wea. Forecasting, 16, 133-144, https:// doi.org/10.1175/1520-0434(2001)016<0133:AEORAR>2.0.CO;2.

Sugier, J., P. Tabary, J. Gourley, and K. Friedrich, 2006: Evaluation of dual-polarisation technology at C-band for operational weather radar network. EUMETNET Opera 2 Rep., 44 pp.
Tabios, G. Q., III, and J. D. Salas, 1985: A comparative analysis of techniques for spatial interpolation of precipitation 1. J. Amer. Water Resour. Assoc., 21, 365-380, https://doi.org/10.1111/ j.1752-1688.1985.tb00147.x.

Thorndahl, S., T. Einfalt, P. Willems, J. E. Nielsen, M.-C. ten Veldhuis, K. Arnbjerg-Nielsen, M. R. Rasmussen, and P. Molnar, 2017 Weather radar rainfall data in urban hydrology. Hydrol. Earth Syst. Sci., 21, 1359-1380, https://doi.org/10.5194/hess-21-1359-2017.

TRCA, 2019a: Don River. Toronto and Region Conservation Authority, accessed 26 November 2019, https:/trca.ca/conservation/watershedmanagement/don-river.

_ 2019b: Watershed Features - Humber River. Toronto and Region Conservation Authority, accessed 26 November 2019, https://trca.ca/conservation/watershed-management/humberriver/watershed-features/.

Unduche, F., H. Tolossa, D. Senbeta, and E. Zhu, 2018: Evaluation of four hydrological models for operational flood forecasting in a Canadian Prairie watershed. Hydrol. Sci. J., 63, 1133-1149, https://doi.org/10.1080/02626667.2018.1474219.

Viney, N. R., J. Perraud, J. Vaze, F. H. S. Chiew, D. A. Post, and A. Yang, 2009: The usefulness of bias constraints in model calibration for regionalisation to ungauged catchments. 18th World IMACS Congress and MODSIM09 Int. Congress on Modelling and Simulation, Cairns, Australia, IMACS/MODSIM, 3421-3427.

Vivekanandan, J., D. N. Yates, and E. A. Brandes, 1999: The influence of terrain on rainfall estimates from radar reflectivity and specific propagation phase observations. J. Atmos. Oceanic Technol., 16, 837-845, https://doi.org/10.1175/1520-0426(1999) 016<0837:TIOTOR $>2.0$. CO;2.

Vivoni, E. R., D. Entekhabi, R. L. Bras, V. Y. Ivanov, M. P. Van Horne, C. Grassotti, and R. N. Hoffman, 2006: Extending the predictability of hydrometeorological flood events using radar rainfall nowcasting. J. Hydrometeor., 7, 660-677, https://doi.org/10.1175/JHM514.1.

Wang, L.-P., S. Ochoa-Rodríguez, J. Van Assel, R. D. Pina, M. Pessemier, S. Kroll, P. Willems, and C. Onof, 2015: Enhancement of radar rainfall estimates for urban hydrology through optical flow temporal interpolation and Bayesian gauge-based adjustment. J. Hydrol., 531, 408-426, https://doi.org/10.1016/j.jhydrol.2015.05.049.

Weber, M. E., J. Y. Cho, J. S. Herd, J. M. Flavin, W. E. Benner, and G. S. Torok, 2007: The next generation multimission U.S. surveillance radar network. Bull. Amer. Meteor. Soc., 88, 1739-1752, https://doi.org/10.1175/BAMS-88-11-1739.

Wijayarathne, D., P. Coulibaly, S. Boodoo, and D. Sills, 2020: Evaluation of radar-gauge merging techniques to be used in operational flood forecasting in urban watersheds. Water, $\mathbf{1 2}$, 1494, https://doi.org/10.3390/w12051494.

Xie, H., X. Zhou, J. Hendrickx, E. Vivoni, H. Guan, Y. Tian, and E. Small, 2006: Evaluation of NEXRAD stage III precipitation data over a semiarid region. J. Amer. Water Resour. Assoc., 42 , 237-256, https://doi.org/10.1111/j.1752-1688.2006.tb03837.x.

Young, C. B., and N. A. Brunsell, 2008: Evaluating NEXRAD estimates for the Missouri River Basin: Analysis using daily raingauge data. J. Hydrol. Eng., 13, 549-553, https://doi.org/ 10.1061/(ASCE)1084-0699(2008)13:7(549).

Zahmatkesh, Z., S. Kumar Jha, P. Coulibaly, and T. Stadnyk, 2019: An overview of river flood forecasting procedures in Canadian watersheds. Can. Water Resour. J., 44, 213-229, https://doi.org/ 10.1080/07011784.2019.1601598.

Zhang, J., Y. Qi, D. Kingsmill, and K. Howard, 2012: Radar-based quantitative precipitation estimation for the cool season in complex terrain: Case studies from the NOAA Hydrometeorology Testbed. J. Hydrometeor., 13, 1836-1854, https://doi.org/10.1175/ JHM-D-11-0145.1. 